\title{
The impact of personality on behavior in five prisoner's dilemma games
}

Citation for published version (APA):

Boone, C. A. J. J., de Brabander, B., \& van Witteloostuijn, A. (1996). The impact of personality on

behavior in five prisoner's dilemma games. NIBOR, Netherlands Institute of Business Organization and Strategy Research. NIBOR Research Memorandum No. 002 https://doi.org/10.26481/umanib.1996002

Document status and date:

Published: 01/01/1996

DOI:

10.26481/umanib.1996002

Document Version:

Publisher's PDF, also known as Version of record

\section{Please check the document version of this publication:}

- A submitted manuscript is the version of the article upon submission and before peer-review. There can be important differences between the submitted version and the official published version of record.

People interested in the research are advised to contact the author for the final version of the publication, or visit the DOI to the publisher's website.

- The final author version and the galley proof are versions of the publication after peer review.

- The final published version features the final layout of the paper including the volume, issue and page numbers.

Link to publication

\footnotetext{
General rights rights.

- You may freely distribute the URL identifying the publication in the public portal. please follow below link for the End User Agreement:

www.umlib.nl/taverne-license

Take down policy

If you believe that this document breaches copyright please contact us at:

repository@maastrichtuniversity.nl

providing details and we will investigate your claim.
}

Copyright and moral rights for the publications made accessible in the public portal are retained by the authors and/or other copyright owners and it is a condition of accessing publications that users recognise and abide by the legal requirements associated with these

- Users may download and print one copy of any publication from the public portal for the purpose of private study or research.

- You may not further distribute the material or use it for any profit-making activity or commercial gain

If the publication is distributed under the terms of Article $25 \mathrm{fa}$ of the Dutch Copyright Act, indicated by the "Taverne" license above, 
The impact of personality on behavior in five prisoner's dilemma games

C. Boone, B. de Brabander \& A. van Witteloostuijn

$\mathrm{NIBOR/RM/96/02}$

http://www.unimaas.nl/ document/fdewb.htm

J.E.Lit.code: M21

$n i b o r$

Netherlands Institute of

Business Organization

and Strategy Research

University of Maastricht

Faculty of Economics and Business Administration P.O. Box 616

6200 MD Maastricht

The Netherlands

Phone: ++3143 - 3883805 
Fax : ++3143-3258495

\section{THE IMPACT OF PERSONALITY ON BEHAVIOR IN FIVE PRISONER'S DILEMMA GAMES}

BY

Christophe BOONE ${ }^{1}$, Bert DE BRABANDER ${ }^{2}$ and Arjen van WITTELOOSTUIJN ${ }^{1}$

\footnotetext{
This study was undertaken as part of a course on applied game theory at the Faculty of Economics and Business Administration of the University of Limburg. We thank our co-lecturers - Hans Peters and Marc van Wegberg - for providing their support in organizing the experiment. Moreover, we thank Woody van Olffen for his help while managing the data.

1 University of Limburg, Faculty of Economics and Business Administration, Department of Management Sciences, P.O. Box 616, 6200 MD Maastricht, The Netherlands.

2 University of Antwerp (RUCA), Faculty of Applied Economics, Middelheimlaan 1, 2020 Antwerp, Belgium.
} 


\section{ABSTRACT}

The industrial organization of transactions has changed dramatically during the past decade (Thompson and Wright, 1988). Several scholars have discussed and documented the phenomenon of what has been called 'the shrinking organization' (Ford and Farmer, 1986; Lichtenberg, 1992). The apparent failure of 'hierarchies' has been accompanied with the growing importance of cooperation in modern business. The latter poses a serious challenge to managers, especially in the Western world. The reason is that American and European managers are educated to be competitive and to maximize their self-interested objectives (Frank, Gilovich and Regan, 1993). Moreover, cooperation is not socially embedded in these societies - as this is, for instance, the case in Japan. The purpose of this paper is to contribute to the understanding of the determinants of cooperative behavior. Until now, most scholars have concentrated on macro-determinants, such as differences between the Western world and Japan (e.g., Kawasaki and McMillan, 1986). Less attention has been given to the underlying micromechanisms. More specifically, we argue that individuals differ as to their inclination to cooperate. To explore this issue, we conducted an experiment at the University of Limburg (Maastricht, The Netherlands). The main part of this paper is devoted to the investigation of the effect of subjective and objective individual differences on competitive versus cooperative behavior in five Prisoner's Dilemma games. As far as subjective characteristics of individuals are concerned, the paper deals with four personality traits: locus of control, self-monitoring, type-A behavior and sensation seeking. Next, we report results on the influence of objective factors - notably gender, age and prior knowledge of the selfinterest model of economics. In addition, the conditions of the five games were varied to analyze the role of a number of situational determinants in explaining (non-)cooperative behavior. In this respect, the predictions which follow immediately from established game theory will be contrasted with the findings of previous experimental research. Finally, the implications of our findings are discussed. 


\section{CONTENTS}

1. INTRODUCTION

2. THE PRISONER'S DILEMMA

3. THEORETICAL BACKGROUND AND HYPOTHESES 6

3.1 Situational determinants of (non-)cooperative behavior 6

3.2 Individual differences and (non-)cooperative behavior 13

$\begin{array}{ll}\text { 3.2.1 Locus of control } & 14\end{array}$

$\begin{array}{lll}3.2 .2 & \text { Self-monitoring } & 17\end{array}$

$\begin{array}{lll}\text { 3.2.3 } & \text { Type-A behavior } & 18\end{array}$

$\begin{array}{lll}3.2 .4 & \text { Sensation seeking } & 19\end{array}$

$\begin{array}{lll}3.2 .5 & \text { Objective characteristics } & 21\end{array}$

4. METHODS 24

4.1 Subjects and procedures 24

$\begin{array}{lll}4.2 & \text { Measures } & 27\end{array}$

$\begin{array}{lll}4.3 & \text { Data analysis techniques } & 30\end{array}$

5. RESULTS AND DISCUSSION 31

$\begin{array}{lll}5.1 & \text { Descriptive statistics } & 31\end{array}$

5.2 Individual-level analyses 34

5.2.1 Situational determinants of (non-)cooperative behavior 34

$\begin{array}{ll}\text { 5.2.2 Individual differences and (non-)cooperative behavior } & 37\end{array}$

5.2.2.1 Exploratory analyses $\quad 37$

5.2.2.2 Intermediate evaluation 42

5.2.2.3 Multivariate analyses $\quad 43$

$\begin{array}{lll}5.3 & \text { Dyad-level analyses } & 46\end{array}$

6. CONCLUSION 48

APPENDIX $\quad 55$

REFERENCES 
The industrial organization of transactions has changed dramatically during the past decade (Thompson and Wright, 1988). For instance, a tendency toward vertical disintegration can be observed in many industries. Child (1987) discusses this phenomenon on the basis of an analysis of U.K. firms - in sectors such as distribution, electronics, foodstuff and textiles. A similar evolution is reported by Jarillo (1988) for the U.S. Furthermore, several case studies on vertical disintegration in companies such as Benetton, British Leyland, British Steel Corporation, Chrysler and Rank-Xerox have been published (Child, 1987; Shutt and Whittington, 1987; Johnston and Lawrence, 1988). Also, horizontal disintegration has gained popularity in the business world. After decades of intensified diversification the credo 'back to the core business' now drives strategy-making in many firms (Goold and Luchs, 1993). A striking example of horizontal disintegration is the recent partition of the U.K. chemical company ICI in a bulk and a specialty firm. This phenomenon of 'the shrinking organization' (Ford and Farmer, 1986) - both vertically and horizontally - has been analyzed systematically by Lichtenberg (1992), who reports that "[t]he extent of American firms' industrial diversification declined significantly during the second half of the 1980s: The mean number of industries in which firms operated declined $14 \%$, and the fraction of single-industry firms increased $54 \%$... . This decline in diversification, due in large part to intense takeover activity during the 1980s, contributed to U.S. productivity growth" (1992: 427).

The apparent failure of the hierarchical governance structure is the result of increasing environmental dynamism in combination with an emphasis on innovation and flexibility in corporate strategies (Boone and Verbeke, 1991; Teece, 1992). The phenomenon of disintegration has been accompanied by the rapid development of new hybrid organizational forms somewhere in between 'markets and hierarchies'. Such governance structures "[c]an facilitate complex coordination beyond what the price system can accomplish, while avoiding the dysfunctional properties sometimes associated with hierarchy" (Teece, 1992: 1). Examples of hybrid organizational forms are strategic alliances, partnerships, coalitions, research consortia and various forms of network organizations (Powell, 1990; Ring and Van de Ven, 1992). The main distinguishing feature of these cooperative arrangements is that reliance on trust is a necessary condition for successful transacting (Ring and Van de Ven, 1992). Statistics clearly reveal that the incidence of, for example, strategic alliances has increased significantly in the 1980s, both worldwide as well as within Europe and the U.S. (Van Wegberg, Van Witteloostuijn and Roscam Abbing, 1994).

The growing importance of cooperation in modern business poses a serious challenge to managers, especially in the Western world. The reason is that American and European managers are educated to be competitive and to maximize their self-interested objectives (Frank, Gilovich and Regan, 1993). In other words, they are inclined to perceive the outcome of transactions as a 'zero-sum game'. Cooperation is not socially embedded in Western societies - as this is, for instance, the case in Japan. In this context, Kawasaki and MacMillan (1986) have observed the willingness of large Japanese manufacturers to absorb part of the component suppliers' risks. For example, in most supply contracts prices are determined upon 'cost-plus' principles as opposed to 'fixed-price' agreements. In the latter case, the supplier would bear the full risk of the transaction. 
Apart from the increasing importance of cooperative arrangements between firms, as indicated above, the issue of cooperation within firms is of course of continuing interest to the theory and practice of management (Aktouf, 1992; Earley, 1993). Broadly speaking, the external performance of an organization is facilitated by a cooperative attitude within and among task groups internal to the organization. The underlying intuition is common sense: groups which have to spend much time on handling conflicts, either among members of the group itself or with other groups within the organization, are distracted from performing the productive tasks that reflect their very reason of existence. For example, it is hard to imagine that a top management team will be successful if its members are involved in a struggle for competency.

The purpose of this paper is to contribute to the understanding of the determinants of cooperative behavior in general, be it in the context of inter-organizational contacts or intra-organizational task groups. ${ }^{1}$ Until now, most scholars have concentrated on macro-determinants, such as differences between the Western world and Japan (Boone and Verbeke, 1991) and differences between industries (Bidault, Laurent and Segla, 1992). Less attention has been given to underlying micro-mechanisms. More specifically, we argue that individuals differ as to their inclination to cooperate. A case in point is the study of Cox, Lobel and McLeod (1991). One of their findings is that Asian, Black and Hispanic Americans act more cooperatively in a Prisoner's Dilemma game than Anglo-Americans. The main part of this paper is devoted to the investigation of the effect of individual differences on competitive versus cooperative behavior in five Prisoner's Dilemma games. Furthermore, the conditions of the games were varied to analyze the role of a number of situational determinants in explaining (non-)cooperative behavior. In this respect, the predictions which follow immediately from established game theory will be contrasted with the findings of previous experimental research.

Section 2 shortly describes the logic of the Prisoner's Dilemma game. Attention will be given to the applicability of this mixed-motive game to real business settings. Specific hypotheses concerning the occurrence of competitive versus cooperative choices in a Prisoner's Dilemma context are presented in Section 3. We first focus on a number of situational determinants of (non-)cooperative behavior (Subsection 3.1) - notably the (in)finiteness of the horizon and the payoff structure. Next, we elaborate on the potential influence of subjective and objective characteristics of individual players (Subsection 3.2). As far as subjective characteristics are concerned, this paper deals with four personality traits: locus of control, self-monitoring, type-A behavior and sensation seeking. Subsequently, we speculate on the impact of objective factors - notably gender, age and prior knowledge of the self-interest model of economics. Information on subjects, procedures and measures is provided in Section 4. The results are reported and discussed in Section 5. The paper concludes with an appraisal of the implications of our findings in Section 6.

In advance, a final remark is worth making. By applying the experimental method to the study of

\footnotetext{
${ }^{1}$ Of course, the above only provides examples within the domain of economic behavior. It is not difficult to find other illustrations in such fields as the political, psychological and sociological sciences. In effect, the issue of cooperative - as opposed to competitive - behavior is relevant in all situations where human beings (have to) interact.
} 
the impact of three clusters of variables - notably (i) objective individual characteristics, (ii) subjective personality features and (iii) changes in the rules of the game - on the inclination of individual players to either compete or cooperate, this paper steps into two rich traditions of empirical research: experimental economics and experimental psychology. First, since the early 1960 s and particularly during the early 1980s the experimental method has gained a significant market share in empirical economics (Day, 1992). Experimental economics deals with both individual decision making (Grether, 1992) and aggregate market functioning (Plott, 1989). The prime focus of experimental economics has been and still is on the impact of environmental contingencies on individual (decision-making) and aggregate (market-process) economic behavior. Second, psychology has a century-long tradition of studying individual behavior - of whatever kind - in an experimental setting (Murphy and Kovach, 1972). What differentiates experimental psychology from experimental economics is the former's emphasis on individual idiosyncracies, including personality features (Pruitt and Kimmel, 1977). This paper merges both perspectives by taking account of the influence of environmental contingencies and individual idiosyncracies on behavior in an economic game setting.

\section{THE PRISONER'S DILEMMA}

The Prisoner's Dilemma game has been used extensively to model competitive versus cooperative behavior, both in the field of economics (Raiffa, 1982; Rasmusen, 1990) and psychology (Pruitt and Kimmel, 1977; Dawes, 1980). The two-party version is the most widely-used class of Prisoner's Dilemma games (Pruitt and Kimmel, 1977; Cox, Lobel and McLeod, 1991). Each party has to choose independently from two options: cooperation (C) or defection (D). ${ }^{2}$ The payoff of one party depends upon the choice made by the other party. Therefore, the general form of the Prisoner's Dilemma setting can be represented by Table 1's 2 X 2 matrix (Kuhlmann and Marshello, 1975: 923).

\section{INSERT TABLE 1 ABOUT HERE}

The payoff to the left of the comma in each cell is the outcome of party I. Party II's payoff is given to the right of the comma. $\mathrm{R}$ indicates the reward for mutual cooperation, $\mathrm{S}$ refers to the sucker's payoff, $\mathrm{T}$ denotes the temptation to defect, and $P$ is the punishment for mutual defection (Kuhlman and Marshello, 1975). The payoff structure in Table 1 represents a Prisoner's Dilemma game if and only if the following inequalities are satisfied: (a) $\mathrm{T}>\mathrm{R}>\mathrm{P}>\mathrm{S}$, and (b) $2 \mathrm{R}>\mathrm{T}+\mathrm{S}>2 \mathrm{P}$ (Kuhlman and Marshello, 1975; Pruitt and Kimmel, 1977; Rasmusen, 1990).

Consider the example where $T=600, R=300, P=-30$, and $S=-600 .^{3}$ The dilemma resides in the fact that the best possible outcome for all parties concerned results when each party refrains from trying to maximize her or his own self-interest - that is, when both parties choose $C$ [with final payoff

\footnotetext{
${ }^{2}$ The term 'competition' is also used to label the D-option (Pruitt and Kimmel, 1977). In this paper, both terms will be used to indicate 'non-cooperative' choices.

${ }^{3}$ These are the payoffs used in the present study in four of the five games (Section 3).
} 
$(300,300)]$. However, the latter payoff combination is not an equilibrium outcome. The reason is that defection (D) is a dominant strategy ${ }^{4}$ for both parties (Rasmusen, 1990). No matter what the other party does, a player can always increase her or his payoff by defecting unilaterally. If party II chooses $D$, party I is better off by choosing $D$ with a final payoff of $(-30,-30)$. If party II decides to cooperate (C), party I is better off by selecting $D$ [final payoff $(600,-600)]$. Thus, it is to each individual's advantage to defect. According to standard game theory, the outcome (D, D) is a dominant strategy equilibrium (Rasmusen, 1990). It is, however, not a 'desirable' equilibrium because when both parties defect, both are worse off.

It is important to mention that, although the $2 \times 2$ game is the most widely-used variant, other classes of Prisoner's Dilemma games can be distinguished as well - notably N-party games and Noption games with $N>2$ (Pruitt and Kimmel, 1977). Dawes (1980) argues that the N-party game is more representative of real-world situations than the traditional two-party setting. Cox, Lobel and McLeod (1991), however, report that the findings with the N-party game coincide with those of the two-party variant. Theoretically, this is true for specific classes of the so-called Problem of the Commons games (Gibbons, 1992: 27-29). ${ }^{5}$ In this study, we therefore prefer to use simple two-party games.

The Prisoner's Dilemma has far-reaching applications in the social sciences (Bierman and Fernandez, 1993). Rasmusen (1990: 29) comments that "[w]henever you observe individuals in a conflict that hurts all of them, your first thought should be of the Prisoner's Dilemma". Rasmusen (1990) gives several examples of situations where Prisoner's Dilemmas are likely to crop up: oligopoly pricing, auction bidding, salesman effort, political bargaining and arms races. Additional examples are the escalation of advertising outlays and manufacturers squeezing the profit margins of suppliers, leading to low component quality. In an insightful book, Leibenstein (1987) shows that even the low productivity problem inside firms can be modeled as a Prisoner's Dilemma game. He argues (1987: 58) that "[w]e see the problem as one in which low productivity exists because both management and employees have chosen wage-working condition packages (and their related productivity implications) which, while they are very much better than the 'logical' Prisoner's Dilemma solution, are nevertheless much lower than they need be" (emphasis in original).

A very intriguing aspect of such puzzles as low productivity, escalating advertising outlays, poor quality of components is that the Prisoner's Dilemma aspect of those problems is frequently overlooked (Leibenstein, 1987; Rasmusen, 1990). This is not surprising in a culture where maximization of selfinterest is highly valued and taken for granted. In this respect, it is worthwhile to note that according to game theory "[t]he assumption that rational players will choose dominant strategies is quite powerful and not terribly controversial" (Bierman and Fernandez, 1993: 196). Recall that the choice of dominant

\footnotetext{
${ }^{4}$ Here we refer to the strategy concept in mathematical game theory, which may conflict with strategy notions in the literature on strategic management (Mintzberg, 1987). Formally, a strategy is "a rule that tells [the player] which action to choose at each instant of the game, given his information set ..., [which] includes whatever the player knows about the previous actions of other players" (Rasmusen, 1990: 24).

${ }^{5}$ To be precise, the Prisoner's Dilemma is a two-player variant of the N-person Problem of the Commons. Note that with $\mathrm{N}>2$ the degrees of freedom in terms of the rules of the game expand rapidly. For example, the payoffs may then depend upon the number of cheaters.
} 
strategies in a Prisoner's Dilemma situation leads to every party being worse off. However, we argued in the introduction that decision makers are apparently becoming increasingly aware of the benefits of cooperative behavior.

\section{THEORETICAL BACKGROUND AND HYPOTHESES}

\subsection{Situational determinants of (non-)cooperative behavior}

To analyze a number of situational determinants of (non-)cooperative behavior five different games (I to V) were offered to our subjects. As the subjects study business administration or economics (see Section 4 for details), we choose to present the Prisoner's Dilemma as an oligopoly (duopoly) pricing problem. Each game consists of twelve rounds of choices, except for game IV where eight rounds were played (see below). In the first two games, subjects played against a fictive party, receiving no information on the choices made by that party in each round. Therefore, these games are essentially 'one-shot' or non-interactive games. ${ }^{6}$ In the last three games, dyads were formed and subjects played repeated games. That is, choices are made simultaneously and independently in each round, after which subjects are informed of the choice made by the other party. The latter games are more realistic than the simple one-shot games (Bierman and Fernandez, 1993), and allow to analyze the dynamics of (non-)cooperative behavior. The instructions and payoff structures of the games can be found in the Appendix (see also Section 4).

The Prisoner's Dilemma game received - and stil receives - much attention in both the theoretical literature (mainly in economics) and the experimental tradition (dominated by psychology). The predictions of established game theory (Rasmusen, 1990; Gibbons; 1992; Bierman \& Fernandez, 1993) concerning the behavior of individuals in a Prisoner's Dilemma game do not always coincide with the findings of previous experimental research. The hypotheses, formulated below, therefore aim at contrasting the predictions of game theory with the 'actual' behavior of players in a Prisoner's Dilemma setting.

The first non-interactive game can be considered as a baseline measure of (non-)-cooperative behavior. It gives an impression of the subjects' inclination to pursue a competitive or cooperative strategy. According to game theory, 'rational'7 players will choose to defect. It is generally accepted that when each player in a one-shot game has a dominant strategy, as in a Prisoner's Dilemma, then these strategies will be chosen (Bierman and Fernandez, 1993). Not surprisingly, experimental research has revealed that most groups prefer the competitive strategy in a one-shot setting (Kahn, Hottes and Davis, 1971). It should be stressed, however, that this rationality concept of game theory does not seem to be equally applicable in every culture. More specifically, Cox, Lobel and McLeod (1991) report that

\footnotetext{
${ }^{6}$ For a lucid overview of types of games see Gibbons (1992).
}

${ }^{7}$ We put the adjective rational between brackets, since this label is overworked. That is, the notion of rationality has many connotations that have triggered heated - and largely unproductive - debates in the social sciences (Van Witteloostuijn, 1988; Van Witteloostuijn, 1992). Here, rationality refers to the game-theoretical (or, for that matter, neo-classical) assumption of subjective maximization of expected utility under restrictions. 
individuals from collectivistic cultural traditions (Asian, Black and Hispanic Americans) behave more cooperatively than individuals with individualistic cultural backgrounds (Anglo-Americans). Apparently, individualistic rationality (i.e., game-theoretical rationality) co-exists with collectivistic rationality which prescribes cooperation (Van Lange, Liebrand and Kuhlman, 1990). In the present study, we expect that the level of cooperation in the first game will be very low, consistent with the game-theoretical prediction, for two reasons. First, the subjects in the present study are Dutch. The Dutch society is known to have an individualistic cultural tradition (Hofstede, 1991). ${ }^{8}$ Second, our subjects are graduate students of business administration or economics. Frank, Gilovich and Regan (1993) clearly show that economists behave in more self-interested ways than non-economists. They compared the choices of economics majors with nonmajors in a one-shot Prisoner's Dilemma game. They report that, for a total of 534 choices between cooperation and defection, the defection rate was 60.4 percent for economics majors as compared to only 38.8 percent for nonmajors. They also present preliminary evidence to shed light on the reason for this impressive difference. It appears that "[e]xposure to the self-interest model commonly used in economics alters the extent to which people behave in self-interested ways" (Frank, Gilovich and Regan, 1993: 159; see also Subsection 3.2). Therefore, the following hypothesis (H1) relating to cooperation in baseline game I can be formulated.

H1 The degree of cooperative behavior in non-interactive game I will be very low due to the individualistic cultural background of the subjects and their exposure to the self-interest model of business administration or economics.

The second non-interactive game was designed to analyze whether the likelihood of cooperation depends upon the subjects' expectation of the other party's willingness to cooperate (Pruitt and Kimmel, 1977). More specifically, Pruitt and Kimmel (1977: 375) argue that if an individual does not expect the other party to cooperate, "[s]hort-range defensive considerations ordinarily take precedence over longrange cooperative aims, and the actor also fails to cooperate". Experimental research indeed shows that cooperation is enhanced when cooperation from the other party can be expected (Braver and Barnett, 1976; Pruitt and Kimmel, 1977; Dawes, 1980). The theory of Pruitt and Kimmel (1977), however, is mainly applicable to repeated games in which individuals are likely to (i) develop long-range thinking and (ii) benefit from establishing and/or maintaining continued mutual cooperation (see below). The second non-interactive game we offered to the subjects is essentially a 'one-shot' game. In this case, continued mutual cooperation is less salient. Therefore, it is likely that individuals, trying to maximize their own benefits, are inclined to 'exploit' the other party (i.e., defect) if they expect that party to cooperate. In this respect, it is again interesting to summarize the findings of Cox, Lobel and McLeod (1991).

In their setup, subjects played two successive games, which are essentially the same as the first

\footnotetext{
${ }^{8}$ Hofstede measured the degree of individualism in a society in 50 countries and 3 regions. The highest scoring countries are the U.S., Australia, Great Britain, Canada and The Netherlands (Hofstede, 1991: 53).
} 
two non-interactive games used in the present study. ${ }^{9}$ They manipulated the expectation of cooperation in the second game by giving their subjects contrived feedback concerning the choices made by the other fictive party. More specifically, they told the subjects that the other party had selected cooperative choices for all ten rounds during the first game. Cox, Lobel and McLeod (1991) report that Asian, Black and Hispanic Americans made more cooperative choices when receiving cooperative feedback, as they expected. However, the individualistically oriented Anglo-Americans apparently tried to 'exploit' the cooperative 'sucker'. That is, the number of competitive choices made in the cooperative feedback condition increased significantly. In the present study, we extended the research of Cox, Lobel and McLeod (1991) by varying the uncertainty associated with the feedback given to the subjects in the second game. More specifically, half of the subjects was told that the other party made twelve cooperative choices in twelve rounds in a previous encounter (i.e., consistent feedback). The other half received the message that the other party only made eight cooperative choices out of twelve (i.e., inconsistent feedback). Given the individualistic background of our subjects and the observation that consistent cooperative feedback has more effect on expectations of cooperation than inconsistent information (Pruitt and Kimmel, 1977), the following hypthesis (H2) can be formulated.

H2 Compared with baseline game I, the degree of cooperative behavior in game II decreases, because cooperative behavior is expected from the other party. The incentive to 'exploit' the other party in 'one-shot' game II is more pronounced when individuals are given consistent as opposed to inconsistent cooperative feedback.

The last three games offered to the subjects are repeated (or iterated) Prisoner's Dilemma games. In game III dyads of subjects played twelve successive rounds. In each round, choices are made independently and simultaneously. When both parties have made their choice, they are informed of the action carried out by the other party in that round. The final payoff of each player is the sum of the individual payoffs achieved in each round. According to established game theory, repetition with a finite and known horizon (end game) does not generate cooperation, no matter how many times the game is repeated. As in one-shot games, the theory predicts that 'rational' players will never cooperate when playing a finite and known number of repetitions of a Prisoner's Dilemma (Bierman and Fernandez, 1993). In game-theoretical terminology, it can be proven that the unique subgame-perfect equilibrium in this case, solvable by the logic of backward induction, has both parties choosing to defect in every round (Bierman and Fernandez, 1993). The logic of backward induction is based upon the assumption that "[i]n picking his first action, a player looks ahead to its implications for all the future periods, so it is easiest to start by understanding the end of a multi-period game, where the future is the shortest"

\footnotetext{
${ }^{9}$ The main differences between our games and those of Cox, Lobel and McLeod (1991) is threefold: (a) we used an oligopoly pricing problem, whereas they employed a neutral setting; (b) our games consist of twelve rounds, whilst they offered ten rounds; and (c) the payoff values diverge.
} 
(Rasmusen, 1990: 88). ${ }^{10}$ Consider a game of twelve rounds. In the last period (round 12), there is a unique dominant strategy equilibrium in which both parties decide to defect (as in the one-shot game). That is, no matter what the other party decides to do and no matter the history of the game, a player will always be better off by choosing to defect. Thus, both players can be sure at the onset of the game that the other party will defect in the final period. Given this common knowledge, the only reasonable choice to make for 'rational' players in round 11 is again to defect, as there is nothing to gain from building up a reputation of cooperation (Rasmusen, 1990). The same logic can be applied to any of the preceding rounds, including the first.

Bierman and Fernandez (1993: 420), however, observe that "[b]esides being counterintuitive, the prediction that both players will never cooperate when playing a finite number of repetitions of a Prisoner's Dilemma-type stage game is inconsistent with the outcomes of numerous experiments. When people play such games in experimental settings, they usually cooperate until the near end of the game, at which point cooperation finally breaks down". The reason for this observation is that individuals are not so calculative or shortsighted as game theory suggests (Raiffa, 1982). According to Pruitt and Kimmel (1977), it is precisely this short-term thinking that usually leads to noncooperation in 'one-shot' Prisoner's Dilemma games. Astute players, however, who are engaged in repeated interaction with one another, quickly learn to cooperate and often enter into tacit collusion (Raiffa, 1982). Individuals seem to develop long-term thinking in (finite or infinite) repeated games, because they recognize their dependency on the other party in obtaining a reasonable payoff (Pruitt and Kimmel, 1977). In other words, it is to each parties' advantage to achieve "[t]he goal of establishing and/or maintaining continued mutual cooperation" (Pruitt and Kimmel, 1977: 375). Therefore, two conflicting hypotheses, one based on established game theory ( $\mathrm{H} 3 \mathrm{a})$ and the other on experimental findings ( $\mathrm{H} 3 \mathrm{~b})$, can be proposed.

H3a Compared with baseline game I, the degree of cooperative behavior in game III does not increase, which can be explained by game theory's logic of backward induction.

H3b Compared with baseline game I, the degree of cooperative behavior in game III increases, because in experimental practice the players recognize their mutual dependency in repeated interactions.

Game III is characterized by a finite and known horizon (i.e., twelve rounds). In game IV, we simulated an infinite horizon by specifying that the game would be ended at random. ${ }^{11}$ It is important to mention that game theory reveals that whether the game is infinite or is assumed to end randomly, does not

\footnotetext{
${ }^{10}$ Rasmusen (1990: 88), in fact, quotes Kierkegaard who said that "[1]ife can only be understood backwards, but it must be lived forwards".

${ }^{11}$ The probability of ending the game at each round was set at .1 (i.e., a continuation probability of .9). The game ended by chance at round 8 (see Section 4).
} 
make a drastic difference (Rasmusen, 1990). The main point is that the logic of backward induction is not applicable, because there is no final fixed end point to the game (Rasmusen, 1990; Bierman and Fernandez, 1993). In this case, there does not exist a unique subgame-perfect equilibrium which predicts that 'rational' players will defect in every round, as in game III. In fact, the so-called 'Folk Theorem' (Rasmusen, 1990: 92-94) suggests that a multiplicity of equilibria is possible. For instance, eternal cooperation as well as eternal defection are perfect equilibrium outcomes. ${ }^{12}$ Thus, it can be deduced that on average the degree of cooperation should be higher in a game with random ending (game IV) than in a finite game with known horizon (game III). ${ }^{13}$ Of course, whether this difference can be observed depends upon the validity of the backward induction assumption (cf. Hypothesis H3a). The following hypothesis $(\mathrm{H} 4)$ is therefore conditional on the findings related to Hypothesis 3.

H4 Compared with game III, the degree of cooperative behavior increases in game IV, if H3a cannot be rejected. Otherwise, the degree of cooperative behavior does not change.

In game $\mathrm{V}$, we changed the values of the payoff matrix used in all other games such that the incentive to cooperate increases. That is, the payoff for mutual cooperation (R) was doubled from 300 to 600 , whereas the other payoffs were only increased with one third [i.e., the values for sucker's payoff $(S)$, temptation to defect $(T)$ and punishment for mutual defection $(P)$ were changed from $-600,600$ and -30 to $-400,800$ and -20 , respectively]. Notice that the payoff structure still represents a Prisoner's Dilemma as the two inequalities mentioned in Section 2 are satisfied. The horizon of game $V$ is again finite and known (i.e., twelve rounds). This implies that the logic of backward induction is applicable again. Established game theory then predicts that 'rational' players are likely to defect in each round, as in game III, no matter the increased incentive to cooperate. Experimental reseach, however, suggests that the subjects' behavior - here the degree of cooperation - does depend upon the absolute payoff levels as such - here the profits associated with mutual cooperation - even in a setting with a finite and known end horizon (Pruitt and Kimmel, 1977; Brandts and Holt, 1993). Thus, two conflicting hypotheses, one based on established game theory ( $\mathrm{H} 5 \mathrm{a})$ and the other on experimental findings ( $\mathrm{H} 5 \mathrm{~b})$, can be proposed.

\footnotetext{
${ }^{12} \mathrm{~A}$ key determinant of the likelihood of cooperative behavior in infinitely repeated games is the discount rate. An experimental test of this discounting effect is Feinberg and Husted (1993), who report supporting evidence for the standard game-theoretical hypothesis that high rates of time preference impede the incentives to collude.

${ }^{13}$ Apart from multiple contacts over time, as in the repeated games, there is a literature on multiple contacts in time. That is, game theory predicts that cooperative behavior is enhanced if players meet in multiple markets (Bernheim and Whinston, 1990) - or any other contact point (Van Wegberg, Van Witteloostuijn and Roscam Abbing, 1994) - at each point in time. Experimental studies support this claim (Feinberg and Sherman, 1988; Phillips and Mason, 1992).
} 
H5a Compared with game III, the degree of cooperative behavior does not increase in game V, which can be explained by game theory's logic of backward induction.

H5b Compared with game III, the degree of cooperative behavior increases in game V, because experimental research suggests that the increased incentive to cooperate is effective.

As a final remark, one subtlety is worth emphasizing. Hypothesis $\mathrm{H} 3 \mathrm{~b}$ may be confirmed because the players consider the complete series of games to be the relevant setting (see Subsection 4.1 for detailed information on the experimental procedures). That is, the logic of game theory does not apply to each game in isolation, but rather to the series of the three repeated games - as the dyads of players were not varied over the games. As the timing of the end game (round 12 of game V) was not announced in advance (see, again, Subsection 4.1 on this), players may have behaved as if the horizon would be determined randomly, implying that the logic of backward induction was not applicable until the instructions at the start of game $\mathrm{V}$ were made public. In this interpretation, the confirmation of Hypotheses $\mathrm{H} 3 \mathrm{~b}$ does not imply a falsification of established game theory.

\subsection{Individual differences and (non-)cooperative behavior}

In this section, hypotheses are formulated concerning the potential influence of subjective (i.e., personality traits) and objective characteristics of individuals on (non-)-cooperative behavior. With the exception of gender (Cook and Sloane, 1985; Mason, Phillips and Redington, 1991) and cultural background (Cook and Chi, 1984; Cox, Lobel and McLeod, 1991), the number of studies exploring individual differences in (non-)-cooperative behavior in general and in a Prisoner's Dilemma setting in particular is very limited (Pruitt and Kimmel, 1977). This is somewhat surprising as Kuhlman and Marshello (1975) demonstrated that individuals have tendencies to compete or cooperate in mixedmotive games, where these tendencies - or orientations - are relatively stable. We therefore agree with Pruitt and Kimmel's (1977) observation that the impact of attitudes and personality traits, which are likely to be important in many mixed-motive settings, should be incorporated in future theory and research. In the present study, we focus on four personality traits: locus of control, self-monitoring, type-A behavior and sensation seeking. To our knowledge, the potential influence of these traits on (non-)cooperative behavior in a Prisoner's Dilemma setting has not been studied previously.

Behavior in a Prisoner's Dilemma game can be summarized, in our view, by observing three behavioral outcomes: (1) whether the individual plays cooperatively on average, (2) the extent to which an individual varies or changes her or his strategy from game to game, and (3) whether the individual plays pro-active or re-active. Pro-active behavior refers to a person trying to impose her or his strategy upon the other party, whereas re-active behavior is characterized by simply following the strategy of the other party. The present study aims at explaining these three criteria with reference to both subjective and objective individual differences. Due to the near absence of theoretical and empirical research on this subject, however, we consider it unwise to formulate specific hypotheses on the influence of each individual difference on each of the three outcomes. Thus, in the following only hypotheses are 
presented which can be 'backed up' with theoretical and/or empirical findings. Nevertheless, in Section 5 we will also report results on unpredicted relationships for exploratory purposes. First, however, Section 3 goes into the literature on the impact of the individual's objective and subjective characteristics on the inclination to play competitively or cooperatively in a Prisoner's Dilemma game.

\subsubsection{Locus of control}

Rotter (1966) and his colleagues developed the locus of control construct from the former's (1954) social learning theory. The construct refers to what Rotter calls the individual differences in a generalized belief in internal versus external control of reinforcements (Rotter, 1966). Those who believe in external control (i.e., externals) see themselves as relatively passive agents and believe that the events in their lives are due to uncontrollable forces. Externals consider what they want to achieve as dependent upon luck, chance and powerful persons or institutions. They think that the probability of being able to control their lives by their own actions and efforts is low. Conversely, those who believe in internal control (i.e., internals) see themselves as active agents, and feel that they are masters of their fates and trust in their capacity to influence their environment. Internals believe that they control the events in their lives by effort and skill. It is important to mention that recent research indicates that the locus of control is a fundamental personality trait. First, it has been shown that the locus of control is to a certain extent inherited (Miller and Rose, 1982; Pedersen, Gatz, Plomin, Nesselroade and McClearn, 1989). Second, a number of psychophysiological findings seems to indicate that this individual characteristic is associated with differences in cerebral functioning between internals and externals (De Brabander, Boone and Gerits, 1992). More specifically, it appears that internals rely more on the functions of the left hemisphere for sensory-motor control while they execute laboratory tasks than externals. This conclusion can be deduced from indications of a relatively higher activation of the left hemisphere among internals.

The relationship between locus of control and cooperative behavior has been studied among children but, unfortunately, not among adults (Cook and Chi, 1984; Cook and Sloane, 1985). Cook and Chi (1984) and Cook and Sloane (1985) hypothesize that internal children are more competitive than external children. They base their argument on Bialer (1961: 316), who argues that, on the one hand, the internal children's "[g]reater awareness of their own roles in their own successes and failures cause them to strive harder. This may be described as a growth in competitiveness". Internals, who believe in their own control over events, are prepared to be effective and therefore adopt a more aggressive style of play. Externals, on the other hand, "[b]elieving they have little control over the events, come into a situation already prepared to be helpless. Thus, they display dependency on others and a form of passive cooperation" (Cook and Sloane, 1985: 621). In both studies, the so-called Cooperation Board Game was used to assess cooperative behavior. The game is played by two players sitting opposite to each other in front of a flat, wooden board. Both players hold a pair of strings which are attached to a centrally located marker. The purpose of the game is to move this marker, by manipulating the strings, to any of four goal circles in the center of each side of the board surface. Three types of goals can be reached. First, "[d]yad members can interact simultaneously, quickly moving a marker to a joint goal 
(one on each side of the board), from which both receive a poker chip on that trial. This is considered maximally cooperative behavior. Another possible trial outcome is the attainment of an individual goal (one in front of each child). Although individual-goal attainment does require mutual physical effort, only one member of the dyad receives a poker chip on that trial. The third trial outcome, maximally noncooperative behavior, occurs when both dyad members attempt to pull the marker to their individual goals simultaneously. This kind of interaction is reflected in a longer trial latency, and no goal can be attained on that trial if not resolved by the dyad" (Cook and Sloane, 1985: 623; emphasis in original). The period of time necessary to achieve goals (i.e., latency) is used as an indication of non-cooperative behavior. Cook and Chi (1984) report that, among boys aged 8 to 10 years, external dyads are more cooperative than internal or mixed dyads. These findings are extended by Cook and Sloane (1985), who report a trend for boys - but not for girls - that the more external the dyad, the more cooperative the behavior. Furthermore, they find that "[d]yads of internal locus of control boys who displayed relatively little cooperation on initial trials became more cooperative as the game progressed. In addition, male dyads heterogeneous in terms of locus of control (an internal and an external), who also displayed little cooperation initially, became even less cooperative over trials" (Cook and Sloane, 1985: 619). Thus, it appears that external children are more cooperative than internal ones on average. Although it is of course difficult to judge a priori whether these findings can be generalized to adult subjects, as in the present study, we propose the following hypothesis $(\mathrm{H} 6 \mathrm{a})$.

H6a The degree of cooperative behavior is higher for externals than for internals.

A second proposition as to the locus of control trait follows directly from the very definition of the concept. That is, internals and externals are likely to use different strategies in learning the environmental contingencies of success and failure. An individual in search of success who believes in personal control and who acts consistently, must actively search for the laws according to which the environment reacts to her or his own behavior. The more extensively (s)he probes, the better her or his chances are of detecting the crucial contingencies. It seems very probable that such an individual, confronted with an unfamiliar situation, is likely to engage in extensive trial-and-error behavior. A believer in mere luck, whimsical fate or manipulation by uncontrollable forces cannot expect any significant payoff from such behavior, so it is less likely that (s)he will act this way. This general proposition has been confirmed in experimental research (Lefcourt, 1982; Boone, De Brabander and Gerits, 1991) as well as in field research (Miller, Kets de Vries and Toulouse, 1982; Welsch and Young, 1982). In the present context, it seems therefore likely that internals are more 'eager to learn' the implications of the Prisoner's Dilemma game than externals. This implies that the (non-)cooperative behavior of internals will be less rigid than the behavior of externals. This is the next hypothesis $(\mathrm{H} 6 \mathrm{~b})$. 
H6b Internals are more inclined than externals to vary their (non-)cooperative behavior over the five Prisoner's Dilemma games.

The research cited in the previous paragraph clearly shows that internals are more likely to attempt to control their environment than externals. Moreover, recent findings suggest that internals even have a higher 'need for control' than externals. Burger (1984), who developed a 'need for control' scale (Burger and Cooper, 1979), reports that internals score systematically higher on this scale than externals. Similarily, internals are more resistant to influence and are inclined to maintain personal control, whereas externals are more conforming to influence and responsive to demand characteristics (for a summary see Lefcourt, 1982). Therefore, it can be proposed that, when dyads play a repeated Prisoner's Dilemma, internals will try to impose their strategy on the other party (i.e., to pursue pro-active behavior). Conversely, externals are more likely to follow the strategy of the other party (i.e., to reveal reactive behavior). This is reflected in the final hypothesis $(\mathrm{H} 6 \mathrm{c})$ in this subsection.

H6c In a repeated Prisoner's Dilemma game, the influence of past choices of the other party on current individual (non-)cooperative behavior is lower for internals than for externals.

\subsubsection{Self-monitoring}

Another widely-explored personality trait is called self-monitoring (Snyder, 1974; Snyder and Gangestad, 1986). Snyder (1974) argues that people differ in the extent to which they can and do observe and control their expressive behavior and self-presentation. More specifically, "individuals high in selfmonitoring are thought to regulate their expressive self-presentation for the sake of desired public appearences, and thus be highly responsive to social and interpersonal cues of situationally appropriate performances. Individuals low in self-monitoring are thought to lack either the ability or the motivation to so regulate their expressive self-presentations. Their expressive behaviors, instead, are thougth to functionally reflect their own enduring and momentary inner states, including their attitudes, traits and feelings" (Snyder and Gangestad, 1986: 125). Research indeed suggests that high self-monitors possess greater social sensitivity than low self-monitors (Snyder, 1987). In contrast, persons low in selfmonitoring seem to be less aware of other's reactions - or, at least, are less concerned with them. Baron (1989) argues that the social sensitivity of high self-monitors may assist them in perceiving the goals and motives of others more accurately. Given their sensitivity to others' goals and their concern for desired public appearance, it can be expected that high self-monitors are more cooperative than low selfmonitors. Some evidence can be found in Baron (1989), who studied the relationship between selfmonitoring and the self-reported tendency to handle conflict with others through non-cooperative means (e.g., avoidance or competition) or through relatively cooperative means (e.g., compromise or collaboration). Baron (1989) finds that high and moderate self-monitors report being more likely to 
collaborate and to compromise than low self-monitors. This is captured by the next hypothesis $(\mathrm{H} 7 \mathrm{a})$.

H7a The degree of cooperative behavior is higher for high self-monitors than for low self-monitors.

It follows from the very definition of self-monitoring that the behavior of high self-monitors is guided more by situational cues than the behavior of low self-monitors (Weiss and Adler, 1984). Research indeed reveals that low self-monitors are prone to behave in a manner consistent with their attitudes and values and so not to readily adjust their actions to changing situational conditions (Snyder and Ickes, 1985; Snyder, 1987). Therefore, a similar hypothesis ( $\mathrm{H} 7 \mathrm{~b}$ ) as the one proposed for locus of control (i.e., $\mathrm{H} 6 \mathrm{~b}$ ), albeit for different reasons, can be formulated.

H7b High self-monitors are more inclined than low self-monitors to vary their (non-)-cooperative behavior over the five Prisoner's Dilemma games.

\subsubsection{Type-A behavior}

The type-A behavior has been described in a wide variety of ways since the introduction of the concept by Friedman and Rosenman more than 25 years ago (Appels, 1985; Friedman and Booth-Kewley, 1987). Type-A behavior is described by its discoverers as referring "to the behavior of an individual who is involved in an aggressive and incessant struggle to achieve more and more in less and less time: the idea of hurry sickness" (Friedman and Booth-Kewley, 1987: 783). In any case, type-A persons are characterized by time urgency, interpersonal hostility, aggression, irritability, impatience and a high level of competitiveness (Appels, De Haes and Schuurman, 1979; Glass, 1983; Baron, 1989). Those who have not developed such a behavioral pattern are called type-B persons. It seems reasonable to suggest that type-A persons, due to their impatience and competitiveness, are less likely to show cooperative behavior than type-B individuals. In this respect, it is again interesting to refer to the findings of Baron (1989), who observes that type-A persons report a higher frequency of conflict with subordinates than their type-B counterparts. Second, he reports that type As perceive competition over limited resources as more important causes of conflict than type Bs. Finally, type-A individuals indicated to be less inclined to use accommodation as a conflict-handling method than type-B persons. The accommodation conflict-handling mode implies a strong concern for the views of the other side and a somewhat lesser concern with one's own desires (Kabanoff, 1987). Of course, such a concern could be an important reason for pursuing a cooperative strategy in a Prisoner's Dilemma game. The next hypothesis $(\mathrm{H} 8)$ is the result.

H8 The degree of cooperative behavior is higher for type-B persons than for type-A individuals. 


\subsubsection{Sensation seeking}

Individuals differ fundamentally as to their motivation to experience sensation (Zuckerman, 1979a, 1991; Feij and Van Zuilen, 1984). High sensation seekers are characterized by a strong need to continuously experience new and varied stimuli. They are therefore inclined to actively seek risky and novel situations. Conversely, low sensation seekers prefer stable, safe and predictable situations because of their low arousal tolerance (Zuckerman, 1979a). Research has revealed a substantial genetic determination, and replicated relationships with specific neurophysiological and biochemical variables are suggestive for a biological basis of this motive. More specifically, differences in sensation seeking are related to individual differences in optimal levels of stimulation and arousal (Zuckerman, 1979a). It is argued that the central nervous system of low sensation seekers is very sensitive to stimuli with low intensity. It is, however, less capable to process stimuli of high intensity. The opposite applies to high sentation seekers: they are less sensitive to weak stimulation, but highly re-active to stimuli of high intensity. ${ }^{14}$

Important for the present study is that sensation seeking is associated with the desire to seek novelty, variation and risk (Zuckerman, 1979b; Feij and Van Zuilen, 1984). It is clear that to induce cooperation in a repeated Prisoner's Dilemma game one of the parties has to 'break the ice' and choose to cooperate (i.e., C). That is, one of the parties has to create goodwill and trust so that mutual cooperation can be expected in future rounds (Pruitt and Kimmel, 1977). Such an 'ice-breaking' strategy, however, is risky as it can be assumed that "[t]he subject who first 'breaks the ice' and chooses C does not expect the other to play $\mathrm{C}$ on the same trial but to imitate him on future trials" (Pruitt and Kimmel, 1977: 377). In other words, the one who tries to induce the other party to cooperate runs the risk to end up as the 'sucker'. Because of the risks involved, we expect high sensation seekers to be more cooperative than their counterparts. Furthermore, it is also expected that high sensation seekers are more likely to alternate their strategy over the five games than low sensation seekers because of their strong need for variation and their aversion of repetitive experience. This generates a twofold hypothesis (H9a and $\mathrm{H} 9 \mathrm{~b})$.

H9a The degree of cooperative behavior is higher for high sensation seekers than for low sensation seekers.

H9b High sensation seekers are more inclined than low sensation seekers to vary their (non)cooperative behavior over the five Prisoner's Dilemma games.

\footnotetext{
${ }^{14}$ Research indicates that the confrontation with stimuli of increasing intensity is associated with an increase in brain activity among high sensation seekers but not so among low sensation seekers, where brain activity remains constant or even decreases (Zuckerman, 1979a; Feij and Van Zuilen, 1984). Therefore, the former are also called 'augmenters' and the latter 'reducers'.
} 
It should be mentioned that ongoing research suggests that sensation seeking is a multidimensional personality construct operationalized by subscales with quite different genotypic foundations (Zuckerman, 1979a; Feij and Van Zuilen, 1984; Feij, Orlebeke, Ganzendam and Van Zuilen, 1985). The following four dimensions can be distinguished (Zuckerman, 1979a; Feij and van Zuilen, 1984).

(1) Thrill and adventure seeking (TAS): a desire to engage in activities involving some physical danger or risk.

(2) Experience seeking (ES): the desire to seek novel experiences through traveling, music, art and a nonconforming lifestyle.

(3) Disinhibition (DIS): the need to seek release in uninhibited social activities with or without the aid of alcohol.

(4) Boredom susceptibility (BS): an aversion for repetitive experiences of any kind, routine work and predictable people.

For the sake of parsimony and for reasons of the complete absence of research and theory on the relationship between sensation seeking and cooperative behavior, specific hypotheses for the four dimensions are not developed. We will, however, report results on both 'general' sensation seeking and its four dimensions separately in Section 5 for exploratory purposes.

\subsubsection{Objective characteristics}

In this subsection we elaborate on the potential influence of three objective characteristics: gender, age and prior knowledge of the self-interest model of economics. First, gender differences in cooperative behavior have been studied frequently. The reason, of course, is that gender is easy to observe (Pruitt and Kimmel, 1977). ${ }^{15}$ Moreover, it is still a widely-held belief that females are more cooperative and less aggressive than males (Cook and Sloane, 1985). This belief has been supported in several studies using a variety of tasks, such as the Prisoner's Dilemma game (Sibley, Senn and Epanchin, 1968; Tedeschi, Heister and Gahagan, 1969; Frank, Gilovich and Regan, 1993) and visual-motor tasks like the Cooperation Board Game (Cook and Sloane, 1985). For instance, Frank, Gilovich and Regan (1993) found that the probability of a male defecting in a Prisoner's Dilemma game is almost .24 higher than the corresponding probability for a female. Similar results are reported by Mason, Phillips and Redington (1991), who observed that women tend to be more cooperative than men, but that these differences vanish after 25 periods in a non-cooperative game. Furthermore, research suggests that men are more likely than women to adopt a forceful style in both negotiation and mediation (Kimmel, Pruitt, Magenau, Konar-Goldband and Carnevale, 1980; Lim and Carnevale, 1990). Although a limited number of studies reports inconsistent findings (Cook and Sloane, 1985; Rapoport, Guyer and Gordon, 1976), the majority of findings tends to reveal this stereotypical gender difference, especially among adults. This is reflected

\footnotetext{
${ }^{15}$ Pruitt and Kimmel (1977), for instance, report that gender differences have been explored in at least 68 Prisoner's Dilemma studies in the 1960s and 1970s.
} 
in the following hypothesis $(\mathrm{H} 10)$.

H10 The degree of cooperative behavior is higher for females than for males.

The second objective feature is age. The following hypothesis $(\mathrm{H} 11)$ as to the relationship between age and (non-)cooperative behavior is based on behavioristically-oriented and cognitive-developmental theories. Cook and Sloane (1985: 620) argue that those theories "[w]ould predict an increase in cooperative behavior with age or at least an increase in the capacity for such behavior when it is appropriate and leads to reward".

H11 The degree of cooperative behavior increases with age.

Third, and finally, we investigate the relationship between the extent of prior knowledge of the selfinterest model of economics and (non-)cooperative behavior. As already mentioned above, the findings of Frank, Gilovich and Regan (1993: 159) suggest that "[e]xposure to the self-interest model commonly used in economics alters the extent to which people behave in self-interested ways". This may explain why economics majors are less likely to cooperate than nonmajors. It is clear, however, that all economics majors are not exposed to this self-interest model to the same extent. That is, some students follow 'hard core' economic courses (such as non-cooperative game theory), whereas others choose business courses with a psychological and/or sociological flavor (such as organizational behavior and organization theory). Some evidence can be found in the study of Frank, Gilovich and Regan (1993) that, even among students of economics, the extent of exposure to 'hard core' economics may increase non-cooperative behavior.

These authors presented a pair of ethical dilemmas to students in two introductory microeconomics courses and to a control group of students in an introductory astronomy course on two occassions: during the initial week of class and during the final week four months later. "In one dilemma, the owner of a small business is shipped ten microcomputers but is billed for only nine; the question is whether the owner will inform the computer company of the error. Subjects are first asked to estimate the likelihood that the owner would point out the mistake; and then, on the same response scale, to indicate how likely they would be to point out the error if they were the owner. The second dilemma concerns whether a lost envelope containing $\$ 100$ and bearing the owner's name and address is likely to be returned by the person who finds it. Subjects are first asked to imagine that they have lost the envelope and to estimate the likelihood that a stranger would return it. They are then asked to assume that the roles are reversed and to indicate the likelihood that they would return the money to a stranger" (Frank, Gilovich and Regan, 1993: 168; emhasis in original). The probabilities indicated in the four dilemma's reveal the extent to which the student can be considered to be 'honest'. The instructors of 
both introductory courses of microeconomics differed in the extent to which they emphasized 'hard core' economic concepts. Instructor A, with research interests in industrial organization and game theory, mainly underlined competition as opposed to cooperation. Instructor B, a specialist in economic development, relatively underemphasized these competitive notions. The finding then is that "[o]ne semester's training was accompanied by greater movement toward more cynical ('less honest') responses in intructor A's introductory economics class than in instructor B's. Subjects in instructor B's class, in turn, showed greater movement toward less honest responses than did those in our control group of introductory astronomy students" (Frank, Gilovich and Regan, 1993: 169). ${ }^{16}$ This observation is consistent with the hypothesis that emphasis on the self-interest model tends to inhibit cooperation. Conversily, exposure to courses which emphasize cooperation increases the likelihood of cooperation. This give two subhypotheses ( $\mathrm{H} 12 \mathrm{a}$ and $\mathrm{H} 12 \mathrm{~b})$.

\begin{tabular}{||ll||}
\hline H12a & $\begin{array}{l}\text { The degree of cooperative behavior increases with the extent of exposure to courses } \\
\text { which emphasize cooperation. }\end{array}$ \\
H12b & $\begin{array}{l}\text { The degree of cooperative behavior decreases with the extent of exposure to courses } \\
\text { which emphasize the self-interest model of economics. }\end{array}$ \\
\hline
\end{tabular}

A summary table of the hypotheses and expected signs will be presented after the methods section.

\section{METHODS}

\subsection{Subjects and procedures}

The experiment was incorporated into a two-week 'skills training course' in applied game theory for graduate students of business administration or economics at the University of Limburg (Maastricht, The Netherlands). Note that the faculty's business administration curriculum contains much economics. The purpose of the course is to learn students to apply and understand the consequences of formal game theory as described by, for instance, Raiffa (1982) and Rasmusen (1990). The course focused on three topics of game theory: in the first part students played bidding games, in the second part they applied coalition theory and the third part the Prisoner's Dilemma problem was analyzed. The course started with a plenary session in which 52 students, who subscribed to the skills training course, were asked to fill in a questionnaire so as to measure their subjective and objective characteristics. Concerning the purpose of the experiment, we only announced that it was designed to deepen their and our understanding of behavior in a game-theoretical setting. The students were promised feedback on the major findings of the research project after completion of the course. We also guaranteed strict confidentiality of the information provided by the questionnaires.

\footnotetext{
${ }^{16}$ It should be mentioned that these results cannot be explained by the fact that students were not randomly assigned to the two economics classes. First, the students of both classes did not differ on their initial level of 'honesty'. Second, changes in 'honesty' were analyzed rather than the absolute level of cynicism.
} 
The five Prisoner's Dilemmas were presented to the subjects in a fixed order at the onset of the third part of the course. At that time, ten students had already quitted from the course. ${ }^{17}$ In order not to influence the subjects' 'spontaneous' behavior, we took care that no reference was made to the Prisoner's Dilemma in the first two parts of the course. The order of presentation and main characteristics of the games are summarized in Table 2.

\section{INSERT TABLE 2 ABOUT HERE}

The experiment took place in one large room. When entering the room, every subject drew a random number from a box. This number corresponded to a specific seat number in the room. On every row four subjects were seated, each of them separated from the others by three empty seats. Pairs of subjects were formed to play the repeated Prisoner's Dilemma games (i.e., the last three games). These random dyads consisted of the subjects sitting side-by-side.

As already mentioned in Section 3, the Prisoner's Dilemma was presented as an oligopoly pricing problem. One of the authors first announced that five games were to be played, and that detailed information on each game would be provided just before the game involved started. Then, he showed and explained the general payoff structure of the first game (see the Appendix) The subjects could make two choices: setting a low price (corresponding with a competitive choice) or setting a high price (corresponding with a cooperative choice). The instructional phase fully and redundantly explained the interdependent nature of the payoffs, so that the consequences of different combinations of choices was clearly understood (see also Frank, Gilovich and Regan, 1993). Following Schlenker, Helm and Tedeschi (1973), we avoided the use of such terms as 'compete', 'cooperate', 'defect' and 'sucker' so to insure a neutral instructional set.

The pace of the experiment was strictly controlled by one of the authors, who gave instructions as to when and how to make choices in each game. The subjects received a booklet with the instructions of each game and a corresponding response sheet. To trace the arguments and motives underlying the choices made, we asked the subjects to write down the reason why they behaved competitively or cooperatively in each round of the game at hand. Every instruction was clarified by the experimenter, using sheets, at the beginning of each game. Game I and II involved making twelve choices in a row against a fictive party. At the onset of game III, the experimenter announced each subject's opponent for the three repeated games. The subjects received a booklet with small blanco sheets and were instructed in each round to make a choice independently and simultaneously. Next, subjects had to write down their choice on such a blanco sheet. After every subject had written down her or his choice, the experimenter instructed the parties to exchange the sheets with their choice. Following this exchange, subjects marked their choice, the opponent's choice and their payoff on a response sheet. This procedure was repeated for each round in the three repeated games. Of course, apart from the

\footnotetext{
${ }^{17}$ Students at the University of Limburg are allowed to quit from a course at any moment. It is unlikely that those students gave up because of the experiment, as the quit ratio does not differ from those of other courses.
} 
exchange of sheets no communication was allowed. Recall that in game IV we simulated an infinite horizon by specifying that the game could end after each round with a probability of 11 (i.e., a continuation probability of .9). The game in fact ended by chance after round 8 .

Following standard experimental gaming, the subjects were instructed to maximize their payoff during the experiment (Schlenker, Helm and Tedeschi, 1973; Pruitt and Kimmel, 1977). We motivated the subjects by means of the announcement that the top-three players in terms of the accumulated payoff over the whole course would receive a token for music records. ${ }^{18}$ We also appealed to the social motivation for prestige by telling the subjects that the ranking of payoffs, including the players' names, would be announced in public in a final plenary session at the end of the course.

As already mentioned above, we preferred to present the Prisoner's Dilemma games in a fixed order. Such a procedure makes it difficult to disentangle the effect of order from the effect of different game conditions on (non-)cooperative behavior. The effect of order - in the sense of the time elapsed has been studied by, for instance, Rapoport and Chammah (1965) and Keser (1992). First, Rapoport and Chammah (1965) found that cooperation in a multiplay Prisoner's Dilemma game is a U-shaped function of the time elapsed. The percentage of cooperative moves initially declines, but then cooperation increases between trials 30 and 60. Second, Keser's (1993) finding is that if subjects play an (identical) multi-stage but finite duopoly game twice in a row, the experience effect increases cooperative behavior in the second game. In the present study, the confounding effect of time (e.g., learning) is especially problematic when the outcomes of game IV and V are compared with game III (Hypotheses 4, 5a and 5b). In that case, the same dyads play three repeated games in a row. The findings related to these hypotheses should therefore only be viewed as tentative. An order effect, however, is an unlikely candidate to account for eventual differences between game III and game I (Hypotheses $3 \mathrm{a}$ and $3 \mathrm{~b}$ ). The reason is that both games are fundamentally different. Furthermore, there is nothing to 'learn' from game I that can be used in game III, because the subjects did not receive any feedback on the payoff consequences of their choices. It should be stressed, however, that the main purpose of the present study is to analyze whether individual differences relate to (non-)-cooperative behavior and the dynamics of choices in different games. This research question, of course, does not impose any specific rule upon the order in which the games have to be presented.

Finally, the number of observations is not constant over the entire experiment due to a limited number of missing data and the fact that ten subjects quitted during the course. In order not to loose too much observations, we preferred to work with all the available information. Therefore, we will indicate the sample size in each of the subsequent analyses.

\section{$4.2 \quad$ Measures}

Locus of control was measured with the well-known and widely-used Rotter scale (Rotter, 1966), translated in Dutch by the authors. The original scale contains 29 forced-choice items, 23 of those items

\footnotetext{
${ }^{18}$ The payoff of the first two games could not be calculated as subjects played against a fictive party without a predetermined strategy.
} 
being designed to measure the locus of control expectancies (and 6 being filler items). Each item consists of a pair of statements. The respondents have to choose between an internal and an external alternative. The following pair of statements is a clear example: "Many times I feel that I have little influence over the things that happen to me" (external alternative) and "It is impossible for me to believe that chance or luck plays an important role in my life" (internal alternative). A total locus of control score is obtained by counting the number of external alternatives chosen (with minimum 0 and maximum 23). The number of filler items in the present study was increased to 14 in order to make the purpose of the test more obscure. The reliability of our Dutch translation was demonstrated in several studies (Boone, De Brabander, Gerits and Willemé, 1990; De Brabander, Boone and Gerits, 1992; Boone, 1992). Cronbach's alpha (Cronbach, 1951) amounts to .78 ( $n=51$ with 23 items) in this sample and concurs with the internal consistencies reported by Rotter (1966) and Robinson and Shaver (1973). The value of alpha calculated for this sample is well above the lower limits of acceptability, generally considered to be in the .50 to .60 range (Nunnally, 1978).

Research on the basis of exploratory factor analysis shows that several dimensions can be observed in the answers to the Rotter scale (see for a summary Ashkanasy, 1985; Marsh and Richards, 1987). Several scholars therefore questioned the validity of locus of control as a unitary concept. This conclusion, however, is unwarranted for two reasons. First, it should be remembered that the Rotter scale intends to measure generalized control expectancies. This implies that the scale consists of items assessing locus of control beliefs in a wide sample of different life situations and should therefore be regarded as an additive scale (Rotter, 1975). Second, recent confirmatory factor analyses demonstrate the existence of a higher order factor that corresponds to the generalized control expectancies (Ashkanasy, 1985; Marsh and Richards, 1987). Ashkanasy (1985: 1338) concludes that "[f]rom an operational point of view, however, it appears that Rotter's scale, despite an overhead of irrelevant items, measures a useful an essentially unitary personality variable".

The most widely-used measure of self-monitoring is the Self-Monitoring Scale developed by Snyder (1974). As with the Rotter scale, several researchers criticized this scale, which consists of 25 items, because it does not seem to tap a single-person variable (see for instance Briggs and Cheek, 1986). In a reply to these criticisms, however, Snyder and Gangestad (1986: 125) report data suggesting "[t]hat the measure does tap a meaningful and interpretable causal variable with pervasive influence on social behavior, a variable reflected as a general self-monitoring factor". In the same article the authors also present a new, ameliorated 18-item measure of self-monitoring. It is a Dutch translation of this scale that was used in the present study. Respondents are asked to indicate for each of the 18 items whether the statement is true, mostly true, false or rarely true as applied to their life. An example of such a statement is the following item: "In different situations and with different people, I often act like very different persons". The items are keyed in the direction of high self-monitoring. A total score is obtained by counting the number of high self-monitoring answers (with minimum 0 and maximum 18). Cronbach's alpha equals .70 in the present sample $(n=52$ with 18 items). Similar values are reported by Snyder and Gangestad (1986).

The two primary methods of assessing type-A behavior are the structured interview method, 
developed by Friedman and Rosenman (1974), and a paper-and pencil questionnaire called the Jenkins Activity Survey (JAS; Jenkins, Zyzanski and Rosenman, 1979). It is widely accepted that the structured interview is the best method to measure type-A behavior (Appels, 1985; Appels, Mulder and Van Houtem, 1985). The reason is that the interview not only allows to take account of the content of responses of subjects, but also to discount their overt behavioral style indicative of the type-A behavioral 'syndrome' (such as speech rate, speech volume and response latency; see Friedman and BoothKewley, 1987). The JAS, however, is more heavily used in research because of its convience in studies with larger samples. In the present study, we used a Dutch adaptation of the original JAS (Appels, 1985; Appels, Mulder and Van Houtem, 1985). The adapted version contains 24 items. An example is: "Are you hurried when going to work, even if you have enough time?". The number of response categories varies from three to five, depending on the question asked. The response categories which are indicative for type-A behavior receive score 1 and the other categories score 0 (implying a minimum score of 0 and a maximum score of 24 in total; see Appels, 1985). The Dutch JAS reveals satisfactory reliability and validity values (Appels, 1985). The Cronbach's alpha coefficient in the present study is .67 $(n=51$ with 24 items) and is therefore acceptable. It is, however, considerably lower than the value reported by Appels (1985) for a sample of 3169 middle-aged men (with an alpha of .84).

The so-called 'Spanningsbehoeftelijst' (SBL), developed by Feij and Van Zuilen (1984), was used to assess sensation seeking. The SBL is a Dutch adaptation of the American Sensation Seeking Scale (more specifically, the SSS-form V; see Zuckerman, 1979a). The SBL consists of 67 items, 51 of which are designed to measure sensation seeking (the other items are fillers). The respondents are asked to indicate on a five-point scale to what extent they agree with each of 51 statements $(1=$ strongly disagree, $2=$ moderately disagree, $3=$ do not know, $4=$ moderately agree and $5=$ strongly agree). The scores of 15 items are reversed, so that a high score corresponds to high sensation seeking. The SBL allows to assess both the scores on the four dimensions of sensation seeking (TAS, ES, DIS and BS) and a total sensation seeking score. ${ }^{19}$ The following statements are examples of SBL-items: "I would like to learn to fly" (TAS-item), "I like to wander around in a strange city on my own, even if it means getting lost" (ES-item), "I usually don't enjoy a movie or play when I can predict what will happen in advance" (BS-item) and "I like wild, uninhibited parties" (DIS-item). Extensive research among young adults suggests that the SBL is a reliable and valid measurement instrument (Feij and Van Zuilen, 1984). The Cronbach alpha coefficients in the present study are .69 for TAS ( $n=52$ with 12 items), .71 for ES ( $n=$ 51 with 14 items), .73 for BS ( $n=52$ with 13 items), .75 for DIS ( $n=52$ with 12 items) and .79 for total sensation seeking ( $\mathrm{n}=51$ with 51 items). These values concur with those reported by Feij and Van Zuilen (1984).

The questionnaire also provides information on age and gender $(0=$ male and $1=$ female $)$. Finally, we measured the extent of the subject's prior exposure to courses emphasizing either

\footnotetext{
${ }^{19}$ The number of items to assess TAS, ES, BS and DIS are 12, 14, 13 and 12, respectively. Scores for these dimensions are obtained by summing up the responses to the individual items. Thus, the maximum scores for TAS, ES, BS and DIS are 60, 70, 65 and 60, respectively. The total sensation seeking score is the sum of the item averages of the four subdimension (implying a minimum of 4 and a maximum of 20) (see Feij and Van Zuilen, 1984).
} 
competition ('hard core economics') or cooperation. The subjects were presented a list of twelve courses and were asked to mark the courses they had already attended. Four of those courses (i.e., 'Economic theory of strategy', 'Strategic management', 'Game theory' and 'Cases in strategic management') mainly stress the self-interest model of economics (i.e., competition). Four other courses (i.e., 'Organizational behavior', 'Economic theory of organization', 'Strategic thinking' and 'Cases in external and internal organization analysis') are not restricted to competition issues, but also emphasize the importance of cooperation in economic life. ${ }^{20}$ Two variables were created by simple counting the number of competitive and cooperative courses indicated by the subjects.

Several criterion variables were used, depending on the type and level of analysis performed. It suffices to mention here that competitive choices (i.e., setting a low price) were coded as 0 and cooperative choices (i.e., setting a high price) as 1 . In Subsection 4.3, which deals with data analysis techniques, information on the operationalization of the dependent variables is provided.

\subsection{Data analysis techniques}

Two levels of analysis were explored in the present study: individual choice behavior and paired (or dyad) behavior. Below the corresponding data analysis techniques are introduced briefly only, as it is of course beyond the scope of the current paper to reproduce technicalities.

Concerning the individual as the unit of observation, we will start with simple exploratory, bivariate analyses and graphical representations of the average level of cooperative behavior in each game as a function of each individual characteristic separately. For this purpose, following other researchers (Uejio and Wrightsman, 1967; Cox, Lobel and McLeod, 1991), we employ the total number of cooperative choices in each game as our primary measure of cooperative behavior. Recall that in game IV only 8 rounds were played. In order to standardize measures over the five games, we multiplied the total number of cooperative choices in game IV with the ratio 12/8. To assess the effect of individual differences on strategy changes from game to game, we computed the variance of the total number of cooperative choices per game for each individual. Rank correlation analysis will be applied to test for the significance of individual differences. Next, we will interpret the data set as a pooled crosssection/time-series sample in order to analyze the dynamics of game behavior in the three repeated games (see also Mason, Phillips and Redington, 1991; Mason, Phillips and Clifford, 1992). This procedure permits us to investigate (i) the unique contribution of each individual difference to the explanation of cooperative behavior and (ii) whether subjects behaved pro-active or re-active. In that case, we will use Logistic Regression, with the individual choice made in each round serving as the dependent variable (see Section 5).

In order to check the convergent validity of our findings, we pushed the analysis one step further in the three repeated games by looking at the pair (or dyad) as the unit of observation. Moreover, this allows us to explore the dynamics of the behavior of mixed dyads (e.g., male versus female and external

\footnotetext{
${ }^{20}$ The distinction between competitive versus cooperative courses is based upon our judgement of the actual content of the modules.
} 
versus internal). For this purpose, the dependent variable is the sum of the cooperative choices made by each dyad in each round $(0,1$ or 2$)$. In Table 3 , the hypotheses and expected signs of the relationships are summarized.

\section{INSERT TABLE 3 ABOUT HERE}

\section{RESULTS AND DISCUSSION}

\subsection{Descriptive statistics}

Descriptive statistics and the rank correlations among the variables under study are reported in Table 4.

\section{INSERT TABLE 4 ABOUT HERE}

For the moment, we will focus our discussion on the relationships between the individual difference variables. The rank correlation coefficients between locus of control, self-monitoring and sensation seeking are moderate to high. More specifically, internal subjects score higher on the self-monitoring $(r$ $=-.39$ and $p<.01$ with $n=51)$ and sensation-seeking $(r=-.51$ and $p<.001$ with $n=50)$ scale. In addition, the correlation between self-monitoring and sensation seeking is rather low $(r=.37$ and $p<.01$ with $n=51$ ). These relationships are as expected, as will be explained below.

Consider first the relationship between locus of control and self-monitoring. Recall that the Rotter scale measures the control expectancies of individuals in a wide range of different life domains (such as achievement related domains, political life and social events). This implies that internals are also more likely to be confident in their ability to control social interaction. Since the self-monitoring of expressive behavior is one important way to influence social interaction, it is not surprising that internality is correlated positively with such expressive behavior.

The relationship between locus of control and sensation seeking has been analyzed previously by Zuckerman (1979a). He argues that since high sensation seekers score often high on autonomy, one may expect a close relation to an internal locus of control. However, the correlation he reports between sensation seeking and locus of control is contrary to the tentative hypothesis. Zuckerman's findings, however, may be sample-specific. He comments that "[t]he positive findings are mostly confined to older patient and prisoner groups and are rare in college students. The relationship between sensation seeking and externality may be due to an interaction of the sensation seeking with the situation of confinement or with age. There is a certain realistic component to a belief in an external locus of control when one is hospitalized or imprisoned. Perhaps the sensation seekers among the patients and prisoners are more sensitized to the loss of control over their reinforcements" (1979a: 174).

There are at least two other reasons to expect internality to be associated with high sensation seeking in 'normal' populations. First, research suggests that internals are more likely to take risks than externals, because they have more confidence in their ability to control the new situation (for a summary see Boone, 1992). Similarly, Lefcourt (1982) reports several findings suggesting that internals perform better in ambiguous and stressful situations than externals. Thus, apparently both internality and high 
sensation seeking are related to the propensity to take risks. Second, there is a striking similarity between the finding that low sensation seekers are very sensitive to stimuli with low intensity (i.e., they are called 'reducers') and recent psychophysiological locus of control research. More specifically, externals seem to be less able than internals to control the physiological processes related with the input of sensory stimuli. That is, externals are more easily 'aroused' when confronted with irrelevant (i.e., 'non-signal' stimuli) than internals, and they habituate slower to such stimuli (Blankstein, 1984; De Brabander, Boone and Gerits, 1992). As high arousabilty implies high sensitivity to stimuli of low intensity, these findings suggest that similar physiological processes may lie at the heart of both locus of control and sensation seeking differences between individuals.

Given the argument that self-monitoring can be viewed as an important manifestation of locus of control expectancies in social interaction and given the observation that the latter is related to sensation seeking, it is not surprising to find a positive correlation between self-monitoring and sensation seeking. It is moreover interesting to notice that the pattern of correlations among the subdimensions of sensation seeking is highly similar to those reported by Feij and Van Zuilen (1984). That is, TAS is relatively independent of the other dimensions, whereas ES, BS and DIS are positively but modestly interrelated (see Table 4). Not surprisingly, type-A subjects report being more susceptible to boredom (BS) than type-B persons $(r=.37$ and $p<.01$ with $n=51)$. The JAS-scores are not related to the other personality variables and thus seem to tap a distinct individual characteristic. This finding is consistent with previous research showing no relationship between type-A behavior and locus of control (Appels, 1985). We are not aware of previous studies linking type-A behavior, self-monitoring and sensation seeking.

Inspection of the rank correlation matrix reveals that there are some important differences between male and female subjects. First, females have a more external perception of control than males (Mann-Whitney $U$ test: $U=213$ and $p<.05$ with $n=51$ ). This is consistent with several previous findings (McGinnies, Nordholm, Ward and Bhanthumnavin, 1974; De Brabander and Boone, 1990; Boone, 1992). The cause of this difference is suggested by McGinnies, Nordholm, Ward and Bhanthumnavin (1974: 454) by indicating that "[t]here are, in all probability, few countries where women have achieved equality of opportunity with males and where they possess freedom of self-determination to the same extent as males. In any case, the present females probably were reporting a perception of their status which was matched, at least for them, by social reality". Second, a very surprising finding is that females score higher on type-A behavior than males (Mann-Whitney $U$ test: $U=155$ and $p<.01$ with $n=51$ ). Apparently, the females in our sample exhibit more time urgency, aggression, impatience and competitiveness than males. This finding, of course, does not correspond with the widely-held belief that females are more 'easy going' than males. It may be that females who choose to study economics are in some important way 'different' from other women. That is, attraction and selection processes may operate so that only highly competitive female economics students are retained. Third, males have higher total sensation seeking scores than females. This difference is mainly due to differences in disinhibition scores (DIS: a Mann-Whitney $U$ test gives $U=171$ and $p<.01$ with $n=51$ ). Recall that DIS refers to the need for seeking release in uninhibited activities such as drinking, sex and gambling. The same gender differences have been consistently reported by Zuckerman (1979a) and Feij and Van 
Zuilen (1984). It is likely that the underlying reason must be located in stereotypical role expectations as to the behavior of males and females. Fourth, males are significantly older than females in our present sample, which is probably by accident.

The last three individual characteristics (age, exposure to cooperative courses and exposure to competitive modules) are relatively independent of the other individual differences (at the .05 probability level) with two exceptions. First, the age-gender relationship has been mentioned above. Second, persons scoring high on BS appear to have followed more cooperative courses than persons scoring low on BS. It may be that boredom susceptability induces students to choose courses that deviate from the mainstream self-interest model of economics that is central to much of the faculty's curriculum.

The discussion above makes clear that the task of disentangling the unique contribution of each individual difference to the explanation of competitive and cooperative behavior is rather difficult. This point will be addressed in the next subsection, which reports the results of multivariate analyses.

\section{2}

Individual-level analyses

\subsubsection{Situational determinants of (non-)cooperative behavior}

Before turning to the effect of individual differences, results are reported on Hypotheses 1 to 5 . The average number of cooperative choices per game is depicted in Figure 1.

\section{INSERT FIGURE 1 ABOUT HERE}

The average number of cooperative choices in baseline game I is extremely low, which is consistent with Hypothesis 1 (mean of game $I=2$ with $s d=3.22$ and $n=41$ ). By way of comparison, Cox, Lobel and McLeod (1991) report an average of 3.03 cooperative choices on a total of 10 rounds in their sample of 75 Anglo-Americans. Apparently, our Dutch subjects are even more individualistically oriented than their American colleagues. A possible reason is that the former subjects are students of business administration or economics, whereas the latter were students from several academic majors.

Consistent with Hypothesis 2 and with the study of Cox, Lobel and McLeod (1991) is the observation that cooperative behavior decreases in game II (mean of game $\|=1.63$ with $\mathrm{sd}=3.48$ and $n=41$ ). A paired t-test, however, shows that this difference is not significant. To analyze whether the incentive to 'exploit' the other party is more pronounced in game II when individuals are given consistent as opposed to inconsistent cooperative feedback, we computed the difference between the number of cooperative choices made in game II and in game I for each individual. ANOVA shows that consistent cooperative feedback is significantly associated with a decrease in cooperative behavior $(F=5.20$ and $p$ $<.05$ with $n=41$ ). That is, the subjects are only tempted to 'exploit' the cooperative 'sucker' when they can be sure that the other party will cooperate in the future. This finding is depicted in Figure 2.

\section{INSERT FIGURE 2 ABOUT HERE}

The effect of repeated interactions is clearly revealed by comparing game III with baseline game I. The 
average number of cooperative choices more than doubled (mean of game $\mathrm{III}=4.45$ with $\mathrm{sd}=4.19$ and $n=42$ ). This difference is highly significant (paired t-test: $t$ value $=3.53$ and $p<.001$ with $n=41$ ), confirming Hypothesis $\mathbf{3 b}$. Apparently, subjects do not use the logic of backward induction within game III when engaged in repeated interactions (Hypothesis 3a). However, this finding cannot be taken for granted, since the players may have applied a game-theoretical logic over the series of repeated games III to V (see the argument at the end of Subsection 3.1). This would imply that the backward induction reasoning cannot be taken seriously, as the students were unaware of the precise timing of the end game (i.e., round 12 of game V). Perhaps, our data permit to discriminate between both opposing interpretations if the players' written accounts of the strategies they chose to pursue have been coded and analyzed. On this, we will report in a second paper.

The average number of cooperative choices in game IV increases, as expected (mean of game IV $=5.25$ with $s d=4.40$ and $n=42$ ). The difference between game III and IV, however, is not significant (evaluated with paired t-test). Therefore, Hypothesis 4 is rejected. Finally, cooperative behavior increases substantially when the incentive to cooperate increases (mean of game $\mathrm{V}=6.95$ with $\mathrm{sd}=$ 4.49 and $n=42$ ). The difference between game $V$ and game III is significant (paired t-test: $t$ value $=3.39$ and $p<.01$ with $n=42$ ). Thus, Hypothesis $5 b$ is confirmed and Hypothesis $5 a$, based on standard game theory, is rejected. As the players were sure of the timing of the end game (in round 12), established game theory cannot explain the findings that there was not only cooperation in the first place (which contradicts the logic of backward induction) but that cooperative behavior even increased from game III to IV (with a random horizon!) to V.

Recall that the findings concerning hypotheses IV and $V$ may be biased due to the fixed order of experimental conditions. Nevertheless, the following conclusions, based on the analysis of the first three games, can be drawn with confidence. First, subjects adapt their cooperative behavior to the conditions of the game. That is, they switch to a more cooperative strategy when engaged in a repeated interaction (game III). This finding does not imply that the subjects suddenly became more altruistic. Indeed, if altruism (or a collective orientation) would be the underlying reason for making cooperative choices, no difference between games III and I would be observed in the first place. Moreover, the baseline games (game I and II) show that the subjects' orientation is highly individualistic. They, however, seem to have understood that cooperation in game III leads to a higher individual payoff. In fact, the rank correlation between the number of cooperative choices and the sum of the payoffs in each round amounts to $.70 \mathrm{in}$ game III $(p<.001$ with $n=42) .{ }^{21}$ Second, the findings suggest that established game theory can only predict behavior in one-shot Prisoner's Dilemma games. In this respect, our results are highly consistent with previous experimental findings. More specifically, particularly the results of game $\mathrm{V}$ reveal that subjects do not seem to apply the logic of backward induction when making choices in finite games. As the end round (12) in game $V$ was announced in advance, established game theory predicts that the players would have chosen the dominant strategy - that is, defection from the beginning (round 1) to the end (round 12). Their actual behavior, however, deviates strongly from this prediction.

\footnotetext{
${ }^{21}$ These rank correlations are .58 and .88 for games IV and V, respectively $(\mathrm{p}<.001$ with $\mathrm{n}=42)$.
} 


\subsubsection{Individual differences and (non-)cooperative behavior}

\subsubsection{Exploratory analyses}

To explore the data, we will first report simple bivariate analyses, looking at the relationship between each individual difference one by one and two main behavioral outcomes of the game [i.e., average cooperation and variance of (non-)cooperative choices). In subsection 5.2.2.3 we focus on the third main outcome - that is, pro-active versus re-active behavior. ${ }^{22}$

To summarize some findings, we also computed an individual 'overall cooperation' score. This score is the average of the number of cooperative choices made in each of the five games. In Table 5, rank correlation coefficients are reported between the individual differences on the one hand ${ }^{23}$ and the number of cooperative choices per game, the 'overall cooperation' score and the variance of the number of cooperative choices on the other. The results will be discussed below.

\section{INSERT TABLE 5 ABOUT HERE}

Locus of control. The average number of cooperative choices in each of the five games for internal and external subjects is depicted in Figure $3 .{ }^{24}$

\section{INSERT FIGURE 3 ABOUT HERE}

Contrary to our expectations, internal subjects made more cooperative choices than external players throughout the five games. The rank correlation between locus of control and overall cooperation amounts to -.37 (see Table 5: $p<.01$ with $n=39$ ). Table 5 and Figure 3 suggest, however, that the difference between internals and externals is particularly apparent in the repeated games (III to $\mathrm{V}$ ), as opposed to the non-interactive games (I and II). Hence, Hypothesis 6 a cannot be confirmed. It appears that previous findings in samples of children are not generalizable to samples of young adults. A combination of possible explanations can be offered for these findings. First, in a recent study Lester $(1992)^{25}$ analyzes the relationship between the locus of control scores of 54 students of economics (with a mean age of 26.2 years) and their answers to the competitive/cooperative scale of Simmons, Wehner, Tucker and King (1988). His finding is that "[s]tudents who have scores indicating stronger belief in an internal locus of control are more motivated to achieve success both by competitive and by cooperative strategies" (Lester, 1992: 594). The latter suggests that both competition and cooperation constitute a

\footnotetext{
${ }^{22}$ In that case, the data set will be treated as a pooled cross-section/time-series sample.

${ }^{23}$ The results on gender differences, which is a categorical variable, will be reported below.

${ }^{24}$ The locus of control scores were split at the median to form groups of 'internals' and 'externals' for Figure 3. The same procedure was used in all the figures with a personality trait as the independent variable.

${ }^{25}$ We were not aware of this study at the conception of the present experiment.
} 
part of the behavioral repertoire of adult internals. ${ }^{26}$ If we combine this finding with the ability of internals to learn about the environmental contingencies of successes and failures (Lefcourt, 1982), then the argument may be that particularly internal adults will adapt their strategy to the requirements of the environment (in terms of payoffs). As cooperation and payoffs are highly correlated in the repeated games, the above reasoning may explain why internals readily shift their strategy toward cooperation in game III, whereas externals fail to do so to the same extent (see Figure 3). In other words, internals may have been more astute in finding the 'right' strategy than externals (Raiffa, 1982).

Second, recall that to induce cooperation in a repeated game it is necessary that one of the parties 'breaks the ice'. This implies that cooperation entails a risk, as the 'ice-breaking' player can always end up being a 'sucker'. Research suggests that locus of control is related to risk-taking behavior (see also Subsection 5.1). More specifically, internal Chief Executive Officers of small companies report taking more risks than external Chief Executive Officers (Miller, Kets de Vries and Toulouse, 1982; Miller, 1983; Boone, 1992). The suggested reason is that externals are more likely than internals to eschew ambiguity and uncertainty, because they have less confidence in their ability to control the new situation.

Third, Pruitt and Kimmel (1977) argue that 'breaking the ice' is more likely when, among other things, the subject has confidence in her or his capacity to influence the other party. It seems obvious that internals, who have a generalized confidence in their ability to control their environment, also have more confidence than externals in being able to influence the behavior of the other party in a Prisoner's Dilemma game.

Fourth, it has already been mentioned that cooperation in a Prisoner's Dilemma setting requires 'trust' in the other party's 'fairness' (Pruitt and Kimmel, 1977). Previous research shows that locus of control is correlated with the scores on the Interpersonal Trust Scale developed by Rotter (1967). That is, internals are more likely than externals to expect that words, promises and verbal or written statements of others are reliable (Phares, 1976). It is therefore possible that internal subjects are more inclined than their external counterparts to interpret an initial cooperative move of the other party in a repeated game as a signal toward continued cooperation. Conversily, a feeling of interpersonal trust may facilitate the likelihood of internals taking unilateral risks.

Finally, Table 5 also suggests that internals are more inclined than externals to vary their (non)cooperative behavior over the five Prisoner's Dilemma games, as expected (Hypothesis 6b). The rank correlation between locus of control and cooperation variance is $-.29(p<.05$ with $n=39)$.

Self-monitoring. High self-monitors played consistently more cooperative than low self-monitors, as Figure 4 reveals.

\section{INSERT FIGURE 4 ABOUT HERE}

\footnotetext{
${ }^{26}$ The studies mentioned in Subsection 3.2.1 concern 8 to 10-year old children. It is likely that young children lack the cognitive ability to understand the complex dilemma when having to choose between competition and cooperation.
} 
Table 5 shows that the highest rank correlations are related to the self-monitoring concept. Hypotheses $7 \mathrm{a}$ and $\mathbf{7 b}$ are clearly confirmed. The rank correlation between self-monitoring and overall cooperation is $.44(p<.01$ with $n=40)$. It is striking that the relationship between self-monitoring and cooperation is, again, more pronounced in the repeated games. The rank correlation with cooperation variance as the dependent variable amounts to $.43(p<.01$ with $n=40)$, indicating that high self-monitors are more inclined to vary their (non-)cooperative choices than low self-monitors.

Type-A behavior. The rank correlations between type-A behavior and cooperation in each of the five games are consistently negative, as expected, but none is significant at the .05 level. Although our findings suggest that type As are somewhat more competitive than type Bs in four of the five games, which is clear from Figure 5, Hypothesis $\mathbf{8}$ cannot be confirmed. Furthermore, no relationship can be observed between type-A behavior and cooperation variance.

\section{INSERT FIGURE 5 ABOUT HERE}

Sensation seeking. The degree of cooperative behavior is higher on average for high sensation seekers than for low sensation seekers (based on total sensation seeking scores: see Table 5). This is summarized in Figure 6.

\section{INSERT FIGURE 6 ABOUT HERE}

Furthermore, it appears that they are also more likely to alternate their strategy over the five games than low sensation seekers [rank correlations are $.28(p<.05$ with $n=39)$ for overall cooperation and $.35(p$ $<.05$ with $\mathrm{n}=39$ ) for cooperation variance]. Thus, both Hypothesis $9 \mathrm{a}$ and $9 \mathrm{~b}$ are confirmed.

Analysis of the four dimensions of sensation seeking suggests that experience seeking (ES) is significantly correlated with both overall cooperation and cooperation variance $(r=.29$ and $p<.05$ with $n$ $=39$, and $r=.29$ and $p<.05$ with $n=39$, respectively). Table 5 also suggests that the relationship between total sensation seeking and cooperation variance is mainly due to boredom susceptibility $(r=$ .39 and $p<.01$ with $n=40$ ). That is, subjects with an aversion for repetitive experiences tend to vary their behavior to a high extent. Figures 7 to 10 depict the findings.

\section{INSERT FIGURES 7 TO 10 ABOUT HERE}

Gender differences. In the present sample, females do not cooperate more, on average, than males. On the contrary, the number of cooperative choices is higher for males than for females in each of the five games, as is clear from Figure 11.

\section{INSERT FIGURE 11 ABOUT HERE}


Thus, Hypothesis 10 is rejected. Mann-Withney $U$ tests reveal that the pronounced difference between males and females in game IV is significant $(U=122$ and $p<.05$ with $n=40)$, but not in the other games. Both the overall cooperation and cooperation variance scores are lower for women than for men, but again not significantly so. Nevertheless, the probability that females are less cooperative than males in each of the five games, conditional upon the absence of a difference between males and females, is less than .05. Two explanations can be offered for this finding. First, we already mentioned that females who choose to study economics may in some way be 'different' compared to other women. That is, attraction and selection processes may operate so that only highly competitive female students are retained. Recall, for instance, the striking result that the female subjects in our sample report to exhibit more type-A behavior than their male collegues. A second but more speculative possibility is that females may have felt more pressure than males to 'escape' from stereotypical gender differences by demonstrating 'rationality' in decision making.

Age. The sign of the rank correlation between age and overall cooperation is positive, as expected, but not significant (see Table 5). It is interesting to note that the relationship between age and cooperation decreases from game IV onwards. The rank correlations are significant in game I $(r=.31$ and $p<.05$ with $n=39)$ and in game III $(r=.35$ and $p<.01$ with $n=39)$. Therefore, it can be argued that Hypothesis 11 is marginally supported. Figure 12 shows that older subjects make more cooperative choices than younger players in the first four games.

\section{INSERT FIGURE 12 ABOUT HERE}

Finally, there is no significant relationship between age and cooperation variance.

Exposure to cooperative courses. The extent of exposure to cooperative courses is clearly related to average cooperative behavior, as expected (Hypothesis 12a: $r=.33$ and $p<.05$ with $n=40$ ). The rank correlations are consistent in each game and especially pronounced in the last game $(r=.39$ and $p<$ .01 with $n=40$ ). Figure 13 confirms this pattern, indicating that high exposure to cooperative courses is associated with more cooperation in each of the five games.

\section{INSERT FIGURE 13 ABOUT HERE}

The rank correlation with cooperation variance is marginally significant only $(r=.24$ and $p<.10$ with $n=$ 40).

Exposure to competitive courses. Figure 14 indicates that increased exposure to competitive courses decreases the likelihood of cooperation in each of the five games, as expected (Hypothesis 12b). However, none of the rank correlation coefficients reported in Table 5 reaches statistical significance. 


\section{INSERT FIGURE 14 ABOUT HERE}

Apparently, exposure to cooperative courses has more impact on cooperative behavior than exposure to competitive courses. A possible reason for this divergent finding is that all the subjects are students of business administration or economics in which market competition and profit maximization are central concepts. The latter may decrease the marginal effect of additional exposure to the self-interest model of economics. Conversily, courses in which cooperation is emphasized, are rather exceptional.

\subsubsection{Intermediate evaluation}

The exploratory survey suggests, as expected, that individuals differ as to their inclination toward competitive and cooperative behavior in Prisoner's Dilemma games. Internal subjects, high self-monitors and high sensation seekers make more cooperative choices on average and are more inclined to vary their strategy over the five games than external subjects, low self-monitors and low sensation seekers. Type-A behavior, however, is not related to overall cooperation or cooperation variance. Concerning the objective characteristics, older subjects reveal somewhat more cooperative behavior than younger subjects, especially in the first games. The data suggest that females are more competitive than males in our sample. Finally, exposure to cooperative courses increases the likelihood of cooperation.

It is also striking to observe that the influence of individual differences on cooperation, except for age, mainly becomes apparent in the repeated games and not so much in the non-interactive settings. This finding is consistent with the argument that personality variables are more important to explain behavior in 'weak' as opposed to 'strong' situations (Weiss and Adler, 1984). We suggest that the repeated games, where individuals are engaged in social interaction, are 'weaker' situations than the non-interactive games. That is, the repeated games are more ambiguous and complex than the noninteractive variants, and therefore impose less constraints upon the subjects' behavior.

Our findings also suggest that internal, high self-monitoring and high sensation-seeking individuals seem to be better able to adapt their behavior to the requirements of the situation, whereas their counterparts are characterized by behavioral rigidity. On a more general level, it is interesting to speculate on the implications of these findings for the 'trait-versus-situation' debate in psychology (see Pervin, 1985, for a discussion). Mischel (1968), for instance, questioned the existence of personality traits as people fail to demonstrate cross-situational behavioral consistency. He (1968: 146) argued that "[w]ith the possible exception of intelligence, highly generalized behavioral consistencies have not been demonstrated, and the concept of personality traits as broad predispositions is thus untenable". Several 'trait' psychologists reacted by arguing that the definition of consistency used by 'situationists' is too restrictive (see, for instance, Epstein, 1979 and 1980). One of the counterarguments is that behavior may seem inconsistent at the phenotypic level, while being highly stable at the genotypic level (see also Funder and Colvin, 1991). Bowers (1973) gives the following example: a woman who is continuously changing her wardrobe, may be consistently fashionable. Our findings indeed indicate that locus of control, self-monitoring and sensation seeking are not so much related to phenotypic behavioral consistency across different situations, but rather to consistent differences in the ability to adapt to 
different situations. Future research, in our view, should concentrate more on the role of personality in explaining behavioral adaptability (i.e., variability) rather than of focusing on phenotypic behavioral consistency. Both theory and research suggest that locus of control (Lefcourt, 1982), self-monitoring (Snyder and Gangestad, 1986) and sensation seeking (Zuckerman, 1979a) are good candidates for such an endeavour.

\subsubsection{Multivariate analyses}

In this section we interpret the data set as a pooled cross-section/time-series sample. The dependent variable is therefore the choice of each individual in each of the 32 trials of the last three games $(0=$ competitive choice and $1=$ cooperative choice; variable name COOP). Ordered Logistic Regressions were performed to predict the likelihood of individual cooperation in each trial. Four of such Logistic Regression models were estimated.

The independent variables in the first model (1) include all the individual differences of the present study in order to assess the unique contribution of each variable in predicting cooperation. This is of course important because of the moderate to high correlations between the independent variables. The following variable names were used: locus of control (LOC), self-monitoring (SELFM), type A (TYPEA), sensation seeking $(S S)^{27}$, gender (SEX), age (AGE), the number of cooperative courses followed (EXPCOOP) and the number of competitive courses followed (EXPCOMP). In the second model (2), two independent variables were added: the trial number (TRIAL) and the the other party's choice in the previous round (OPLAG). The trial number was incorporated to account for the finding that cooperation increases steadily due to game differences (see Figure 1). The second variable was included to account for the history of the game. That is, although individuals make independent choices in each round, these choices are not independent of the choices made by the other party in previous rounds. Incorporating the other party's choice in the previous round allows to assess whether individual differences matter irrespective of the strategy of the other party. In the third model (3), an interaction variable between locus of control and the other party's lagged choices (LOC*OPLAG) was introduced. This interaction variable permits to test Hypothesis $6 \mathrm{c}$, stating that externals are more re-active than internals. More specifically, we expect that the influence of the other party's past choices on current individual cooperative behavior will be lower for internals than for externals. The fourth model (4) includes the interaction variables of OPLAG with every individual difference for exploratory purposes. The results are reported in Table 6.

\section{INSERT TABLE 6 ABOUT HERE}

The parameter estimates (B) of model 1 are highly consistent with the findings of the bivariate analyses reported in Table 5. The main difference is that the results in Table 6 now indicate that the likelihood to play cooperative is higher for females than for males. Recall that the bivariate analysis reported in

\footnotetext{
${ }^{27}$ To limit the number of independent variables, we only analyzed the total sensation seeking scores of the subjects.
} 
Subsection 5.2.2.1 suggests the opposite. Apparently, the fact that males and females differ significantly on several personality characteristics (e.g., type-A behavior) may have masked the true effect of gender on cooperative behavior. The signs of the other parameter estimates are equal to the signs of the rank correlations between each of the individual differences and overall cooperation (see Table 5). The parameter estimates of type-A behavior and age, however, are now statistically significant. Summarizing the results of model 1 , we find that the likelihood of cooperation is higher for internals, high selfmonitors, type Bs, high sensation seekers, females and older subjects. Furthermore, exposure to cooperative courses increases the probability of cooperation, whereas the likelihood of cooperation decreases with exposure to competitive courses. It is important to stress that the parameter estimates are highly significant (except for SEX and EXPCOMP). Thus, although considerable multicollinearity exists between the independent variables, each individual difference uniquely contributes to the explanation of (non-)cooperative behavior.

The results of the second model confirm the pattern reported in Figure 1. That is, the likelihood of cooperation increases when the game proceeds (i.e., positive effect of TRIAL). The parameter estimate of OPLAG (the other party's choice in the previous round) is also highly significant. More specifically, the odds of making cooperative choices [i.e., Prob(event)/Prob(no event)] increases with factor 12 (calculated as $\mathbf{e}^{\mathbf{B}}$ ) if the other party cooperated in the previous round. This result clearly confirms previous experimental findings that cooperation is enhanced when cooperation can be expected from the other party (Pruitt and Kimmel, 1977). More important for the present study is the observation that all the parameter estimates, except for SEX and EXPCOMP, remain statistically significant. Thus, the individual difference variables contribute to explaining (non-)cooperation irrespective of the other party's choice in the previous round. It should be stressed that model 2 is a very conservative test of the influence of individual differences, because those differences do not only influence the subject's own choices but also indirectly the choices of the other party. Indeed, recall that the game strategies of both parties are highly interrelated. Comparing model 2 with model 1 , it comes therefore as no surprise that the absolute values of the parameter estimates decrease.

Model 3 incorporates the interaction variable LOCUS*OPLAG. The parameter estimate is not significant, so Hypothesis $\mathbf{6 c}$ is rejected. More specifically, externals do not seem to follow the strategy of the other party more than internals. Internal subjects are as pro-active (or re-active) as their external counterparts. The other interaction variables between each of the individual differences and OPLAG were incorporated in model 4 for exploratory purposes. Apparently, the model Chi-Square improves significantly $(\triangle$ Chi-Square $=24.14$ and $p<.01)$. Two parameter estimates are significant, namely for TYPEA ${ }^{*} O P L A G$ and SEX*OPLAG. Both estimates are negative, implying that the influence of the other party's cooperative choices on subsequent cooperative behavior is larger for type-B as opposed to typeA subjects and for males as opposed to females. ${ }^{28}$ It appears that type-B and male subjects play more

\footnotetext{
${ }^{28}$ The correlation coefficient between OPLAG and COOP is $.70(\mathrm{p}<.001$ with $\mathrm{n}=558)$ for type-B subjects (median split) and $.55(\mathrm{p}<.001$ with $\mathrm{n}=651)$ for type-A persons. These correlation coefficients amount to .67 ( $\mathrm{p}<$ .001 with $\mathrm{n}=806)$ for males and $.51(\mathrm{p}<.001$ with $\mathrm{n}=434)$ for females, respectively.
} 
re-active (tit-for-tat) than type-A persons and females. Due to the absence of any theory and research, those differences are difficult to explain.

\section{3}

\section{Dyad-level analyses}

To analyze cooperative behavior at the dyad level one would ideally count the number of cooperative choices in each round for every dyad (with three possibilities: both parties play competitive, both parties play cooperative and one of the parties plays cooperative and the other competitive, which reflects mixed choices). Concerning the independent variables three categories for each individual differences could be formed by using median splits (e.g., locus of control: both parties are internal, both parties are external and one of the parties is internal and the other external). Such categorial data can be analyzed systematically using multivariate (hierarchical) Log-Linear models. This technique permits to unravel relationships in complex cross-classification tables. We could not use multivariate Log-Linear models in the present study, however, due to the frequent occurrence of empty cells. The reason is that the number of cells rapidly increases as additional variables are included in Log-Linear models. In the present study, eight individual difference variables are considered. Furthermore, there are only fifteen dyads with full data on each of those differences. In addition, the occurrence of 'extreme' dyads in our sample is rare (e.g., there are only four dyads were both persons score above the median on locus of control). We therefore deemed it unwarranted to apply multivariate Log-Linear models.

Due to the limitations of our sample to perform bivariate dyadic analyses, we opted for simple bivariate analyses. More specifically, three types of dyads were formed for each individual difference variable by using the median splits as indicated above (e.g., both internal, both external and internalexternal dyad). For each of the individual difference variables seperately we compared the average number of cooperative choices in each round made by mixed dyads with the average number of cooperative choices made by dyads of persons scoring both above or both below the median. ${ }^{29}$ These mean differences are then compared for each of the three games in order to analyze the evolution of the behavior of mixed dyads. ${ }^{30}$ Due to the limited number of 'extreme' dyads, a very conservative multiple comparison test was used (i.e., Scheffe's multiple range test). Nevertheless, the results should be interpreted with caution.

In general, it can be expected that the behavior of the mixed dyads will evolve toward the behavior of one of the 'extreme' dyads. Which 'extreme' dyad is the attraction point, depends upon the sign of the relationships reported in the individual-level analyses. For instance, we found that internal subjects are more likely to make cooperative choices. In that case, we expect mixed dyads (internal-external) to evolve toward the behavior of internal-internal dyads - that is, toward mutual cooperation. This reasoning

\footnotetext{
${ }^{29}$ Recall that we, again, consider the data set as a cross-section/time-series sample. In Subsection 5.3's case the unit of observation is of course the dyad (or pair of subjects).

${ }^{30}$ We acknowledge that Chi-Square tests for independence of bivariate cross-tabulations would be more appropriate as the extent of cooperation is a categorical variable. We prefer, however, to analyze average differences in extent of cooperation between dyads for the sake of clarity. That is, cross-tabulation data are tedious to summarize and report. In any case, the conclusions based on both procedures are similar.
} 
is based on the observation of Pruitt and Kimmel (1977) that when a party expects the other party to cooperate, mutual cooperation is induced. The results are reported in Table 7.

\section{INSERT TABLE 7 ABOUT HERE}

In column 5 of Table 7 (labeled 'total'), the average number of cooperative choices per round over the three repeated games is reported. The results are highly consistent with the individual-level findings (see Table 5). That is, internal, high self-monitoring, high sensation-seeking, male and older dyads play more cooperatively - on average - than external, low self-monitoring, low sensation-seeking, female and younger dyads. In addition, dyads with high exposure to cooperative courses reveal significantly more cooperative behavior than dyads with less exposure to such courses. No significant differences can be observed for type-A behavior and exposure to competitive courses. For each of the dyad characteristics, except for age, the average level of cooperation of mixed dyads lies in between the scores of both 'extreme' dyads.

In column 2, 3 and 4 the average number of cooperative choices per repeated game is reported. For four of the eight dyad characteristics (i.e., locus of control, self-monitoring, sensation seeking and exposure to cooperative courses) the expected behavioral pattern of mixed dyads can be observed. That is, the cooperative behavior of mixed dyads increases rapidly over the three games and evolves toward the behavior of dyads consisting of subjects who are both internals, high self-monitors, high sensation seekers and highly exposed to cooperative courses. As a result, in game III no significant differences in average cooperative choices can be observed between the 'extreme' dyads and the mixed couples.

For the gender and type-A dyad characteristics, the pattern of behavior is completely different. That is, the behavior of the mixed dyads remains relatively constant over the three games in comparison with the 'extreme' dyads. It is interesting to note that female and type-A dyads only start to cooperate when the incentive to cooperate increases (i.e., in game $V$ ), whereas cooperation increases steadily for male and type-B dyads. Apparently, the fact that male and type-B individuals are somewhat more cooperative on average (see Table 5) does not lead to an increase in cooperation over time in mixed dyads. These patterns are consistent with the significant interaction effects reported in Table 6. Recall that we found that females and type-A individuals are less likely to cooperate whenever the other party cooperated in the previous round. Nevertheless, the findings remain difficult to explain.

It is interesting to note that the age differences between dyads gradually disappear over the three games. The average number of cooperative choices in game $V$ is approximately the same for the three types of age dyads. Finally, the effect of exposure to competitive courses is, again, negligible as only one difference is statistically significant. More specifically, dyads with low exposure to competitive courses are more cooperative in game IV than dyads with high exposure to such courses.

\section{CONCLUSION}

The main findings of the present study can be summarized as follows. First, the predictions of established game theory only seem to hold 'almost perfectly' if subjects are engaged in 'one-shot' 
Prisoner's Dilemma games. That is, the results of the baseline (non-interactive) games show that the subjects are highly inclined to be competitive. Furthermore, this finding is consistent with other studies exploring the relationship between cultural differences and competition versus cooperation. More specifically, game-theoretical rationality (here, choosing to compete) is more likely to occur for individuals from individualistic cultural traditions. As soon as our individualistically-oriented subjects, however, are engaged in repeated interactions, they rapidly shift their strategy toward cooperation. This observation is consistent with previous experimental findings, but not with game-theoretical predictions suggesting that the logic of backward induction leads to mutual competition in finitely repeated games with known horizon. Thus, astute players quickly learn to cooperate and to enter into tacit collusion, as this is the only way to obtain a reasonable payoff. Recall, however, that a disclaimer is appropriate here as the players may have behaved in game III as if the horizon is determined randomly. Finally, it is interesting to mention that subjects on average opted for a 'tit-for-tat' strategy in the repeated games. That is, their choice behavior is to a large extent determined by the choices made by the other party in previous rounds.

Second, our findings clearly demonstrate that individual differences matter. When we look at both the individual-level (bivariate and multivariate) and the dyad-level (bivariate) analyses, the following findings are especially robust. Internal locus of control, high self-monitoring and high sensation seeking are systematically associated with cooperative behavior. In addition, these characteristics are also associated with a higher variability (i.e., flexibility) in (non-)cooperative behavior over the five games. More specifically, subjects having the abovementioned characteristics readily shift their strategy from competition toward cooperation from the first repeated game onwards, whereas their counterparts seem to behave more rigidly. It is also striking to note that the effect of these three personality variables only becomes apparent in the repeated games and not in the non-interactive settings. This is consistent with the argument of several psychologists that individual differences are more salient to explain behavior in 'weak' as opposed to 'strong' situations (Weiss and Adler, 1984). At a more general level, our findings suggest that at least some personality traits are not so much predictive of cross-situational behavioral consistency, but rather of behavioral adaptability in different situations.

Another finding that is robust over each analysis reported in this paper, is that increased exposure to cooperative courses inflates the likelihood of cooperation. This finding is consistent with the recent research of Frank, Gilovich and Regan (1993), who report that studying economics inhibits cooperation. Apparently, such cooperative courses serve as a force countervailing the high exposure to the selfinterest model commonly used in business administration and economics. Analyses of the behavior of mixed dyads suggest that internal subjects, high self-monitors, high sensation seekers and subjects with high exposure to cooperative modules are able to induce the other party to cooperate. That is, the extent of cooperation in mixed dyads increases gradually to the average level of cooperation observed in dyads in which both parties share the abovementioned characteristics. The last robust finding is that younger subjects tend to play more competitive than older subjects even for the limited age range observed in the present sample. It is peculiar that this age effect mainly becomes apparent in the first games and gradually disappears toward the end of the experiment. 
The findings for gender and type-A behavior are less clear and somewhat inconsistent. The multivariate analyses suggest that the likelihood of competition is higher for type-A as opposed to type-B subjects. The bivariate analyses, however, fail to reveal significant differences, although the direction of the findings remains the same. Difficult to explain is the unexpected 'bivariate' result that female subjects behave more competitive than male subjects. The ordered multivariate Logistic Regressions, however, reveal precisely the opposite. The latter result suggests that personality differences associated with gender may have masked the 'true' effect of sex on cooperative behavior.

In the following, we elaborate on several limitations of the present study and explore some of the associated suggestions for further research. Firstly, it is clear that our findings are based upon a relatively small sample size. The results should therefore be regarded as tentative evidence only, even though several findings appear to be robust over different data-analytical procedures. Further research on larger samples is certainly necessary. Here we plan to replicate our experiments in the courses on applied game theory in the years to come, which implies that we will accumulate a large sample of observations.

Secondly, the questionnaire designed to assess each of the individual differences was administered in one session. Therefore, the moderate to high correlations between several individual differences may have been caused, at least in part, by a 'halo effect' (Podsakoff and Organ, 1986). Such an effect, however, is not very problematic for the interpretation of our findings, because the bivariate results are essentially the same as the multivariate results that assess the unique contribution of each individual difference. Nevertheless, in future research it would be more appropriate to spread the measurement of each personality variable over time.

Thirdly, although the Prisoner's Dilemma is widely used to model competitive versus cooperative behavior, it does not allow in itself to understand the underlying motives or reasons of individuals to cooperate or to compete. Opening this 'back box' is difficult, however, because a multiplicity of not necessarily mutually exclusive reasons and motives can drive behavior in a Prisoner's Dilemma game. Cooperation can be the result of astuteness, insight and learning, interpersonal trust, propensity to take risks, altruism, collective orientation, etc. In addition, it is likely that each of the individual differences included in the present study may be related to each of these motives and reasons in different ways. Why, for instance, do internals cooperate more than externals, even though previous research suggests that internals are more competitive than externals? We argued that differences in learning ability, risk taking and interpersonal trust may have caused this finding. These reasons seem to be acceptable, but are not very precise. Questions such as "Which motive or reason is more important to explain the difference between externals and internals?" and "Do these motives also apply to explain the effect of other individual differences?" remain unanswered. It is clear that both future theory and empirical research is necessary to enhance understanding the processes leading to cooperation. To be sure, several researchers have already tried to open the Prisoner's Dilemma's 'black box' by asking the subjects to write down the reason why they made a competitive or cooperative choice in each round (for an example see Cox, Lobel and McLeod, 1991). In the present study, we used the same procedure. Unfortunately, this additional information is not yet coded and analyzed. We suspect, however, that such 
a procedure is not enough to unravel this complex and subtle problem. In our view, future research on competitive and cooperative behavior should incorporate detailed questionnaires and/or interviews to assess the motives and reasons underlying individual choice behavior.

In our view, motives such as collective orientation and altruism are unlikely candidates to explain the effect of the abovementioned individual differences on cooperative behavior for two reason. First, if indeed these motives are the underlying reasons to cooperate, it is difficult to explain why we could not observe any significant relationship in the first two non-interactive games, except for age. In addition, the extent of cooperation even decreased when subjects received consistent cooperative feedback concerning the behavior of a fictive party (see Figure 2). Second, we analyzed to what extent the individual differences are associated with the subject's inclination to be honest. For this purpose, we presented to our subjects the pair of ethical dilemmas developed by Frank, Gilovich and Regan (1993) so to assess the 'honesty' of individuals. Recall that these dilemmas, one pertaining to a billing error and the other to a lost envelope, are described in Subsection 3.2.5. Subjects were asked to estimate the probability that the owner would report the billing error (1), you would report the billing error (2), a stranger would return your lost envelope (3) and you would return the stranger's lost envelope (4). The higher the probability checked on each of the four dilemmas, the more the subject can be considered to be 'honest'. We assume that 'honesty', as assessed through these dilemmas, requires a collective and altruistic orientation and can therefore be considered as indicative of the latter motives. The rank correlations between the individual differences and each of the four probability estimates are presented in Table 8.

\section{INSERT TABLE 8 ABOUT HERE}

The results in Table 8 show that, except for sensation seeking and gender, the individual differences are not related to the self-reported likelihood of being honest. Apparently, high sensation seekers are less likely to return the stranger's lost envelope $(r=-.39$ and $p<.01$ with $n=39)$ and somewhat less inclined to report the billing error $(r=-.23$ and $p<.10$ with $n=39)$. As the signs of these relationships are negative, 'honesty' cannot account for the finding that high sensation seekers play more cooperative: on the contrary. It is interesting to mention that the probabilities reported by females are somewhat higher than those indicated by males. Mann-Whitney $U$ tests reveal that the difference between males and females is significant for honesty measure 3 and 4 (see Table 8 ). To summarize, our findings suggest that, at least for subjects from an individualistic cultural tradition, altruism and/or collective orientation are unlikely candidates to explain the observed individual differences in cooperative behavior in a Prisoner's Dilemma game setting.

Fourthly, a final limitation concerns the extent to which the results of the present study can be generalized to other settings. This problem, of course, is inherent to every experiment. Nevertheless, two remarks are worth making. First, previous research suggests that the replicability of findings as to the relationship between individual differences and cooperative behavior may delicately depend upon the specific conditions of the experimental setting. In this respect, it is interesting to contrast the findings of 
Rapoport, Guyer and Gordon (1976) with those of Mason, Phillips and Redington (1991). Recall that Mason, Phillips and Redington (1991) observe that females tend to be more cooperative than men at the beginning of an experiment involving a two-person, non-cooperative, repeated duopoly game. These differences, however, vanish after 25 periods. Thus, in the long run no differences could be observed. Rapoport, Guyer and Gordon (1976) report precisely the opposite. That is, they observed no differences in the behavior of males and females in the first 15 rounds of a $2 \times 2$ repeated Prisoner's Dilemma game. After 15 periods and continuing through the end of the game (i.e., 300 rounds), they report that female pairs were persistently less cooperative than male pairs. Mason, Phillips and Redington (1991) argue that this divergent finding may be the result of differences in the bargaining environment. That is, in the experiment of Rapoport, Guyer and Gordon (1976) pairs of subjects could not communicate, but they could visually observe each other - as in our experiment. In the experiment of Mason, Phillips and Redington (1991), however, subjects did not observe their rival nor were they ever aware of the rival's identity and gender. Mason, Phillips and Redington (1991: 228) comment that "[k]nowing the gender of a rival may have crystallized gender motivated differences in behavior causing such differences to persist and apparently become more pronounced over time. This contrast between our experimental results and those reported by Rapoport and his colleagues highlights the importance of context toward determining gender-related differences in behavior". As we used the same experimental procedure as Rapoport and his colleagues, it is not surprising that our results on gender differences correspond more to their findings than to those of Mason, Phillips and Redington (1991).

The fact that our subjects could observe their rival and were seated next to each other, may have led to other idiosyncratic effects which may not be generalizable to an experimental setting in which subjects remain anonymous. For instance, it has already been noted that to induce cooperation in a repeated game one of the parties has to 'break the ice' and make a cooperative choice. Pruitt and Kimmel (1977) argue that 'breaking the ice' is more likely when, among other things, the subject has confidence in her or his capacity to influence the other party. It can be speculated that this confidence decreases if the parties are anonymous. As it is likely that the confidence to influence the other party depends upon individual differences such as locus of control, it is clear that an anonymous setting may suppress the effect of these individual characteristics. In addition, we cannot rule out the possibility that non-verbal communication (such as eye contact) intensifies the relationship between some individual differences and the extent of cooperation. Particularly, these non-controlled processes may have caused, at least in part, the substantial effect of self-monitoring on cooperative behavior. The reason is that high self-monitors, which by definition are better able to use and control their expressive behavior, may have benefitted more from non-verbal communication to induce cooperation than low selfmonitors. It should be stressed, however, that possible differences in the use and control of expressive behavior as such do not explain why high self-monitors choose to play cooperative in the first place. The main point is that our study should be replicated in an anonymous experimental setting to assess whether our experimental procedure has intensified the observed relationships. In any case, such an endeavour is interesting in its own right even if replication in such a setting is not possible. The latter would suggest that individual differences mainly matter in 'real social interaction' and not so much when 
behavior unfolds in an non-social, anonymous vacuum.

A second remark concerns the generalizability of our findings to real-life settings. Although we have argued that the Prisoner's Dilemma game is a useful model to describe many real-life phenomena, this question is difficult to answer. It is clear that the ultimate proof of any extrapolation must be empirical. Nevertheless, Pruitt and Kimmel (1977: 387) argue that "[a]t several points in this chapter, we have advocated efforts to extrapolate from game findings to real-life settings. We suspect that important implications have been missed because such efforts have usually not been made and believe that such efforts will stimulate hypothesis formation". With respect to 'the cooperation wave' sketched in the introduction, our findings suggest that it could be a fruitful - and as yet unexplored avenue for further research to study the relationship between individual characteristics of top managers and a variety of aspects of organizational cooperation. As an example, we have the following research questions in mind: "To what extent are some top managers more sensitive to the dilemma-type character of specific competitive actions than others?", "Are top management characteristics related to the escalation of resources (e.g., advertising and productive capacity) in the course of competition?", "What is the role of top management characteristics in the initiation of interorganizational cooperation?", "Is the extent of inter-organizational trust related to those characteristics", and "Is there any relationship between the failure rate of cooperative arrangements and the characteristics of top managers?". 